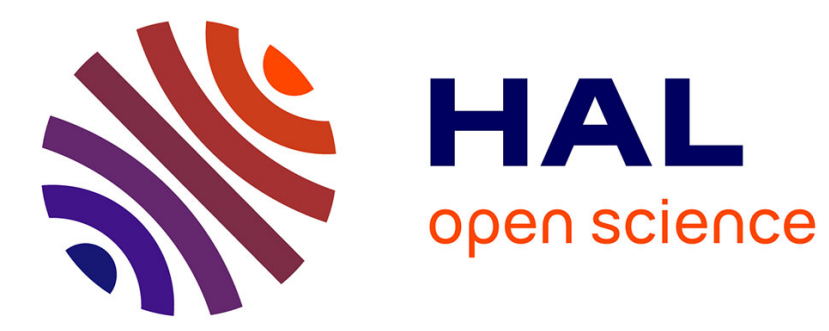

\title{
Geochemical and solute transport modelling for CO2 storage, what to expect from it?
}

Irina Gaus, Pascal Audigane, Laurent André, Julie Lions, Nicolas Jacquemet, Pierre Durst, Isabelle Czernichowski-Lauriol, Mohamed Azaroual

\section{- To cite this version:}

Irina Gaus, Pascal Audigane, Laurent André, Julie Lions, Nicolas Jacquemet, et al.. Geochemical and solute transport modelling for CO2 storage, what to expect from it?. International Journal of Greenhouse Gas Control, 2008, 2 (4), pp.605-625. 10.1016/j.ijggc.2008.02.011 · hal-00568197

\section{HAL Id: hal-00568197 https://hal-brgm.archives-ouvertes.fr/hal-00568197}

Submitted on 22 Feb 2011

HAL is a multi-disciplinary open access archive for the deposit and dissemination of scientific research documents, whether they are published or not. The documents may come from teaching and research institutions in France or abroad, or from public or private research centers.
L'archive ouverte pluridisciplinaire HAL, est destinée au dépôt et à la diffusion de documents scientifiques de niveau recherche, publiés ou non, émanant des établissements d'enseignement et de recherche français ou étrangers, des laboratoires publics ou privés. 


\section{Geochemical and solute transport modelling for $\mathrm{CO}_{2}$ storage, what to expect from it?}

Irina Gaus, Pascal Audigane, Laurent André, Julie Lions, Nicolas Jacquemet, Pierre Durst, Isabelle Czernichowski-Lauriol and Mohamed Azaroual

BRGM - Geosciences for a sustainable Earth, 3 avenue C. Guillemin, 45060 Orléans, France

Corresponding author : Irina Gaus

Address until 25/09/07: BRGM, 3 avenue C. Guillemin, BP6009, 45060 Orléans Cedex2, France, irina_gaus@yahoo.com or i.gaus@brgm.fr, +3323864 4677

Address from 15/10//07: Nagra, Hardstrasse 73, 5430 Wettingen, Switzerland, irina_gaus@yahoo.com, +41(0)56437 1111 


\begin{abstract}
Geochemistry plays an important role when assessing the impact of $\mathrm{CO}_{2}$ storage. Due to the potential corrosive character of $\mathrm{CO}_{2}$, it might affect the chemical and physical properties of the wells, the reservoir and its surroundings and increase the environmental and financial risk of $\mathrm{CO}_{2}$ storage projects in deep geological structures. An overview of geochemical and solute transport modelling for $\mathrm{CO}_{2}$ storage purposes is given, its data requirements and gaps are highlighted, and its progress over the last 10 years is discussed. Four different application domains are identified: long term integrity modelling, injectivity modelling, well integrity modelling and experimental modelling and their current state of the art is discussed. Real challenges are the coupled solute transport and geomechanical modelling, the modelling of impurities in the $\mathrm{CO}_{2}$ stream and pore scale modelling applications.
\end{abstract}

Keywords: solute transport modelling, geochemical modelling, carbon storage, geochemical reactions. 


\section{Introduction}

Carbon capture and storage has been validated by the IPCC (2005) as part of a portfolio of measures to mitigate climate change, and pilot projects multiply around the world. In order for the technology to be deployed at the large scale, its viability in terms of injectivity, the containment of the injected $\mathrm{CO}_{2}$ and the long term safety with respect to humans and the environment needs to be guaranteed. Geochemical reactions play an important role since, due to the corrosive character of $\mathrm{CO}_{2}$, certainly once it is dissolved, they might affect the chemical and physical properties of the wells, the reservoir and its surroundings.

The scientific community identified this potential geochemical feedback on physical properties through highly coupled processes as soon as the technique emerged (eg Czernichowski-Lauriol et al., 1996; Gunter et al., 1997) and during the last 10 years geochemical and solute transport modelling made large progress. It evolved from simple geochemical batch models assuming only interactions between $\mathrm{CO}_{2}$ dissolved in brine and the rocks without taken into account any flow aspects, to three dimensional fully coupled models geochemical and flow models capable of capturing the geological complexity of the storage reservoir and its caprock(s). Currently, solute transport models are numerical codes that include the following processes: two (eg $\mathrm{CO}_{2}$, brine) or three phase $\left(\mathrm{CO}_{2}\right.$, oil, brine) density dependent flow, dissolution of $\mathrm{CO}_{2}$, chemical speciation in the brine, kinetic dissolution and/or precipitation of minerals of the host rock and porosity change in the host rock as a consequence of these processes. For that, the equations of conservation of energy, of momentum, of mass and solute mass together with constitutive laws are coupled in an implicit or explicit manner. A comprehensive review on solute transport modelling in general is given in Steefel et al. (2005) and consequently this will not be repeated here. This paper aims at giving an overview of solute transport modelling for $\mathrm{CO}_{2}$ storage purposes, its underlying data requirements, its main pitfalls and how it can contribute in the future to ensure the viability of carbon storage.

First the importance of assessing geochemical impacts during $\mathrm{CO}_{2}$ storage based on industrial, experimental and natural analogue evidence is demonstrated. Subsequently, different areas where geochemical and solute transport modelling is applied to investigate $\mathrm{CO}_{2}$ storage (long term integrity modelling, injectivity modelling, well integrity modelling and experimental 
modelling) are identified together with their time and space scales of interest. A short history on coupled code development for $\mathrm{CO}_{2}$ storage purposes is given. In a next step the requirements with respect to geochemical data and underlying understanding for a typical $\mathrm{CO}_{2}$ storage site and their impact on the modelled results are discussed. For each of the identified application domains their state of the art and development needs are reviewed. Finally, a summary and an outlook on future geochemical and solute transport modelling topics is given.

\section{Importance of assessing geochemical impacts during $\mathrm{CO}_{2}$ storage}

Although generally pure $\mathrm{CO}_{2}$ is assumed to be little reactive, once in contact with brine, it will form $\mathrm{H}_{2} \mathrm{CO}_{3}$, a weak acid that will almost immediately dissociate:

$\mathrm{H}_{2} \mathrm{CO}_{3}{ }^{-} \rightarrow \mathrm{H}^{+}+\mathrm{HCO}_{3}^{-}$

This causes the $\mathrm{pH}$ of the brine to decrease and makes the brine corrosive to all materials in contact with it (well materials, rocks, pipelines etc). The impact of acid fluids on rocks is illustrated by the damage to our historic buildings under the influence of acid rain. As shown hereafter, there is evidence that this acid attack due to dissolving $\mathrm{CO}_{2}$ can have an important impact during $\mathrm{CO}_{2}$ storage operations and under particular circumstances might determine the success or the failure of the carbon storage project.

Evidence of the impact of $\mathrm{CO}_{2}$ acidification from the industry and in the field is multiple. The corrosive potential of $\mathrm{CO}_{2}$ that contains only a fraction of water (wet $\mathrm{CO}_{2}$ ) is well known (Hesjevik et al., 2002) and becomes clear when transported through pipelines in that stainless steel pipelines are necessary to avoid corrosion damage. In practice it is not possible to transport wet $\mathrm{CO}_{2}$ in low-alloy carbon steel pipelines because of its high corrosion rate (ICCP, 2006). Since water free storage reservoirs are not imaginable, this indicates that once injected, $\mathrm{CO}_{2}$ is likely to dissolve and might induce major geochemical reactions in the reservoir, the well or the overburden under particular circumstances that needs to be evaluated accurately. Indirect evidence of geochemical reactions in the near well environment during industrial operations can be the occasional injectivity difficulties encountered during enhanced oil recovery (EOR) operations as described in Czernichowski-Lauriol et al. (1996), whereby 
traditionally a distinction was made between carbonate and sandstone reservoirs. Generally injectivity changes are poorly explained and vaguely attributed to multiphase flow, $\mathrm{CO}_{2} /$ oil interactions and/or $\mathrm{CO}_{2} /$ mineral interactions (Cailly et al., 2005). Seldom increased injectivity is observed. Hard evidence of the geochemical impacts of injecting $\mathrm{CO}_{2}$ on the field scale is recently becoming available. Fluid and observation well samples from the $\mathrm{CO}_{2}$ injection trial at the Frio formation indicated a significant $\mathrm{pH}$ drop, pronounced increases in alkalinity as well as iron concentrations indicating that almost immediately dissolution reactions take place in the injection area (Kharaka, 2006) due to acidification. Carbonate dissolution has also been identified to influence the brine composition in the reservoir as sampled in the observation wells of the Weyburn project under the influence of $\mathrm{CO}_{2}$ dissolution and $\mathrm{H}_{2} \mathrm{CO}_{3}$ dissociation (Wilson \& Monea, 2004).

Laboratory experiments can further elucidate geochemical reactions caused by $\mathrm{CO}_{2}$ acidification. Several experimental studies have been conducted with $\mathrm{CO}_{2}$ saturated brine on reservoir material under various temperature and pressure conditions to evaluate the geochemical impact of $\mathrm{CO}_{2}$ on the brine and the host rock. Where experiments have been conducted at relatively low temperatures, also due to their relatively short duration, apart from chemical brine changes, this has not generated strong dissolution or precipitation processes other than carbonate dissolution (e.g.Perkins and Gunter, 1995, Gunter et al., 1997 and 2000; Rochelle et al., 2004). Geochemical interactions are observed to be important at higher temperatures as described in Kazuba et al. (2005), performing experiments at $200^{\circ} \mathrm{C}$ and 200 bar and reporting important silicate precipitation next to carbonate precipitation, pointing out also that part of the geochemical interactions might be attributed to brine dessiccation due to the $\mathrm{H}_{2} \mathrm{O}$ dissolving in $\mathrm{SC}-\mathrm{CO}_{2}$. During flow-through experiments the formation of wormholes in limestone cores resulting from brine- $\mathrm{CO}_{2}$ injection has been observed. This dramatically increases the permeability of the rock (Golfier et al., 2001) and illustrates the dissolving power of acid solutions.

Geochemical interaction caused by the presence of $\mathrm{CO}_{2}$ in geological sequences where $\mathrm{CO}_{2}$ is occurring naturally - natural $\mathrm{CO}_{2}$ storage analogues - are particularly valuable since this illustrates the long term impact of $\mathrm{CO}_{2}$ on natural rocks that cannot be reproduced during experiments or field tests. Watson et al. (2004) and Pearce et al. (in prep) observe that the $\mathrm{CO}_{2}$ induced precipitation reactions occur in fractures in cap rocks of natural analogues in Australia and France respectively. While this leads to a reduced injection capillary pressure 
measurement in first, hardly any impact on fracture permeability could be expected in the second case. The formation of minerals on fracture planes of natural $\mathrm{CO}_{2}$ leakage paths, and carbonates and anhydrite in fractures and cracks has been documented by May et al. (2005) and Fischer et al. (2006) respectively. The major geochemical precipitation reaction identified in a couple of natural reservoirs is the precipitation of dawsonite (examples in Baker et al., 1995 and Worden, 2006), an aluminium carbonate mineral that incorporates $\mathrm{CO}_{2}$ and can make up to $17 \%$ of the reservoir (Moore et al, 2005). No major dissolution events in the reservoir are published to our knowledge, although the 3.8\% secondary porosity increase in the $\mathrm{CO}_{2}$ containing sandstone reservoir at Montmiral could possibly be linked to $\mathrm{CO}_{2}$ interactions (Pearce et al., in prep). Surprisingly, chemical equilibrium seems not to be reached in some natural analogues, even when characterised by very long (geological) contact times (Haszeldine, 2005) suggesting that chemical equilibrium might not be the natural state of injected $\mathrm{CO}_{2}$ during the whole duration of the storage period (hundreds of thousands of years).

\section{What do we need to model and how long?}

Geochemical and solute transport modelling has four main application domains when assessing the geochemical impact of $\mathrm{CO}_{2}$ storage, each having its own spatial scale and timeframe of interest (Figure 1) and therefore requiring an adapted modelling approach. An overview of the current state of the art of each of these applications is given in paragraph 6 .

Figure 1 Application domains of geochemical and solute transport modelling relevant to $\mathrm{CO} 2$ storage and their time and space scales.

For long term integrity modelling one aims to assess the ultimate fate of the $\mathrm{CO}_{2}$ injected and its impact on physical properties. Four processes are distinguished: (i) structural trapping, which represents supercritical $\mathrm{CO}_{2}$ trapped in the pore space as a buoyant immiscible fluid phase according to the heterogeneity of the storage zone lithology, (ii) residual $\mathrm{CO}_{2}$ trapping, representing the supercritical $\mathrm{CO} 2$ that is trapped in small pores and cannot be mobilized anymore, (iii) dissolution trapping, which represents $\mathrm{CO}_{2}$ dissolved in the liquid phase (oil or brine), and (iv) mineral trapping, represents $\mathrm{CO}_{2}$ incorporated into minerals due to chemical precipitation. Timescales of impact for these four types of trapping differ from one process to another (Figure 2). The focus in this paper is on sedimentary reservoirs only: (i) depleted oil 
or gas reservoirs, and (ii) saline aquifers. Aquifers offer the advantage of having a larger volume and being the more abundant on the subsurface. Petroleum reservoirs offer the advantage of having the most advanced infrastructure for storage and monitoring of $\mathrm{CO}_{2}$ (Holloway, 1997).

Figure 2. Storage security depends on a combination of physical and geochemical trapping. Over time, the physical process of residual $\mathrm{CO}_{2}$ trapping and geochemical processes of solubility trapping and mineral trapping increase, most likely increasing storage security (IPCC, 2006).

Structural trapping is the main trapping process occurring during the injection period (a couple of decades). The amount of supercritical $\mathrm{CO}_{2}$ remaining in the storage site depends on the rate of dissolution. The brine containing the dissolved $\mathrm{CO}_{2}$ is slightly denser than the original brine, inducing gravity-driven flow and convective fluid circulation (Weir et al., 1996). Because of the difference between the density of the brine with and without dissolved $\mathrm{CO}_{2}$ the mixing time $t_{m i x}$ required for the entire supercritical phase to dissolve depends mainly on the vertical permeability of the porous rock (Ennis-King and Paterson, 2003):

$t_{\text {mix }} \approx \frac{\alpha L \mu}{k_{v} \Delta \rho g}$

$\alpha$ is the density ratio of gas to brine, $L$ is the reservoir thickness, $\mu$ is the viscosity, $k_{v}$ the vertical permeability, $\Delta \rho$ is the density difference between brine with and without dissolved $\mathrm{CO}_{2}$, and $g$ is the acceleration of gravity. Using typical parameters $\left(\phi=0.2, \mu=5 \times 10^{-4} \mathrm{~Pa} \mathrm{~s}\right.$, $k_{V=} 10^{-15}-10^{-14} \mathrm{~m}^{2}, \Delta \rho=10 \mathrm{~kg} \mathrm{~m}^{-3}, L=10 \mathrm{~m}$ and $\alpha=10$ ) for a likely storage site, values of $t_{\text {mix }}$ range from 1,600 to 16,000 years. Estimate of mixing time for the $\mathrm{CO}_{2}$ gas bubble at Sleipner from a 3D model is about 7,000 years for an average $k_{v}=200 \mathrm{mD}$ (Lindeberg and Bergmo, 2002). Ennis-King and Paterson (2003) consider this result as an underestimate due to the dilution of the fingers as they propagate. Mixing by pure diffusion would be a much slower process with a time scale of $(\alpha L)^{2} / D$ where $D$ is the diffusion coefficient. Mineral trapping kinetics is controlled by both dissolution and precipitation kinetics. While the kinetics for carbonates and sulphate reactions is generally fairly rapid, the kinetics of alumino-silicate mineral reactions is much slower (up to thousands of years at ambient temperatures), making mineral trapping a slow process since mainly the latter are involved in $\mathrm{CO}_{2}$ trapping processes. 
For injectivity modelling the time scale of interest is the injection period (eg 25 years) itself and only the direct environment of the borehole is concerned. A massive injection of million tons per year can involve thermal, hydraulic, mechanical but also chemical effects around the open hole section of the injector and the area around it thereby modifying the injectivity index as defined in Figure 3.

Figure 3. Main parameters influencing the injectivity index and their relations between them.

Coupled modelling applications currently concern potential porosity changes due to geochemical interactions (André et al., 2007) and how this affects the injectivity. The impact of preferential flowpaths or fractured flow, and the impact of co-injecting fines are other areas of interest.

Well integrity modelling focuses on the geochemical impacts of the well completion itself, whether the well is the injection well built for the purpose of the $\mathrm{CO}_{2}$ storage project or an abandoned well in case of storage in a depleted oil or gas reservoir. Well completions are made of a sheath of cement surrounding a casing (i.e. pipe) made of steel. The cement sheath has a role of sealing the annulus between casing and borehole walls and prevents fluid migration between formation rocks. This material is also used to plug the casing in case of well abandonment. Along its life, the cement is exposed to various geological fluids (e.g. brine, $\mathrm{CO}_{2}$-rich phase, two-phase fluids). Chemical interactions occur between the brine, the gas mixture and the cement or steel. A typical reaction is the carbonation of the constitutive cement minerals $\left(\mathrm{CSH}^{1}\right.$ and portlandite $\left.{ }^{2}\right)$ by $\mathrm{CO}_{2}$ :

$$
\begin{gathered}
\mathrm{CaO} \cdot \mathrm{SiO}_{2} \cdot \mathrm{H}_{2} \mathrm{O}+\mathrm{CO}_{2} \rightarrow \mathrm{CaCO}_{3}+\mathrm{SiO}_{2} \cdot \mathrm{H}_{2} \mathrm{O} \\
\mathrm{Ca}(\mathrm{OH})_{2}+\mathrm{CO}_{2} \rightarrow \mathrm{CaCO}_{3}+\mathrm{H}_{2} \mathrm{O}
\end{gathered}
$$

This reaction can have consequences on the cement mineralogy, the porosity and indirectly on its transport and mechanical properties (see Figure 3). An increase of permeability, diffusivity, appearance of fissures and annulus space between casing and cement sheath could create preferential paths for leaks to surface. Long timescales have to be taken into account ( $>1000$ years) since well failure is identified as one of the major risks for release of $\mathrm{CO}_{2}$ to the

\footnotetext{
${ }^{1} \mathrm{CSH}$ : Calcium Silicate Hydrate or $\left.\mathrm{CaO} \cdot \mathrm{SiO}_{2} \cdot \mathrm{H}_{2} \mathrm{O}\right)$.

${ }^{2}$ Portlandite : $\mathrm{Ca}(\mathrm{OH})_{2}$.
} 
surface (Bouc et al., 2007). While the horizontal scale of interest is very small (as indicated in Figure 2) - eg a well diameter can decrease with depth from $90 \mathrm{~cm}$ at surface to $21 \mathrm{~cm}$ at $4500 \mathrm{~m}$ depth - , the vertical scale could be very large since the model has to represent the whole length (several thousands of metres) of the well. However, solute transport models taking into account also the vertical scale are not published so far.

Finally, modelling of laboratory or small scale field experiments could allow for the calibration of geochemical and solute transport models, identification of certain case specific chemical or physical parameters and short-term validation of newly developed codes since only for exceptional cases analytical solutions allowing for direct validation are available. These models are developed for the duration (at best a couple of years) and at the scale of the experiment only. Consequently, only interactions that have an impact on the short term can be investigated.

\section{Background and current status of geochemical and solute transport modelling codes.}

Numerical modelling of a storage site requires estimates for both short and long term fate of $\mathrm{CO}_{2}$ injected. Such modelling work can be very demanding in terms of CPU time and memory and results might either be difficult to obtain or limited in terms of precision. Simulations therefore generally focus either on:

- a detailed description of the geochemical fluid rock interaction with complex mineralogical assemblages and dissolution and precipitation kinetics, while using simplified fluid flow in 1D or not taking into account any flow aspect (batch models),

- a detailed reservoir model fluid flow in 2 or 3D with heterogeneous reservoir properties while using a simplified geochemical reactivity model.

Recent numerical modelling for $\mathrm{CO}_{2}$ storage applications can be split into three categories: (i) hydrodynamic modelling simulating structural, residual and dissolution trapping processes, (ii) geochemical modelling simulating batch geochemical reactivity (closed system without any fluid flow) and (iii) reactive transport modelling combining the two previous types of simulations and therefore providing a complete calculation over time of the amount of $\mathrm{CO}_{2}$ trapped through structural, dissolution or mineral trapping. Reactive transport modelling is the 
most realistic modelling technique to quantify long term fate of $\mathrm{CO}_{2}$ as well as other aspects during geological storage, but also the most challenging to complete.

Hydrodynamic modelling - Black oil reservoir simulators provide an efficient tool for performing hydrodynamic simulation to the petroleum engineering community. Using ECLIPSE developed by Schlumberger, Lindeberg et al. (2000) and Lindeberg and Bergmo (2002) have simulated the upward migration of the $\mathrm{CO}_{2}$ bubble in the Utsira formation for the Sleipner project. Gradual dissolution of supercritical $\mathrm{CO}_{2}$ in the brine increases its density with respect to the original brine. This density difference leads to convective flux within the aquifer accelerating the $\mathrm{CO}_{2}$ bubble dissolution in the brine (Lindeberg and Bergmo, 2002). ECLIPSE was also used by Zhou et al. (2004) for modelling $\mathrm{CO}_{2}$ storage in an oil reservoir for enhanced oil recovery purpose for Weyburn project. The TOUGH family of codes developed at the Lawrence Berkeley National Laboratory (Pruess, 1987, 1991, 2004) originally for geothermal reservoir engineering, nuclear waste disposal studies and groundwater studies has been recently adapted for geological storage of $\mathrm{CO}_{2}$ allowing simulations of $\mathrm{CO}_{2}$ injection into deep saline aquifers (Weir et al., 1996, Pruess and Garcia, 2002, Xu et al., 2003). A code intercomparison study has been carried out to evaluate discrepancies between different simulators using different test problems associated with $\mathrm{CO}_{2}$ injection (Pruess et al., 2004).

Gas mixture modelling has been more recently incorporated in hydrodynamic modelling in order to provide simulations considering injection of $\mathrm{CO}_{2}$ in gas reservoirs consisting of methane. Once again, compositional simulators used in the petroleum industry provide the more detailed modelling work. $\mathrm{CO}_{2}$ injection into natural gas reservoirs for combining storage with enhanced gas production has been simulated in the case of K12B site in the North Sea, the Netherlands (van der Meer et al., 2004; Audigane et al., 2007(b)) using the black oil simulator SIMED developed by the CSIRO Petroleum (Australia) and also an adapted version of TOUGH2 to model the gas mixture of $\mathrm{CH}_{4}$ and $\mathrm{CO}_{2}$ (Oldenburg and Benson, 2002).

Batch geochemical modelling - Batch geochemical modelling provides an estimate of the geochemical fluid rock interactions occurring within the formation when brine is saturated with $\mathrm{CO}_{2}$. During batch modelling no flow is taken into account (0 dimensions). Based on a given mineral assemblage and the initial speciation of the aqueous phase enriched in dissolved $\mathrm{CO}_{2}$, mineral dissolution and/or precipitation reactions are calculated and controlled with a 
kinetic rate. Feedback on porosity due to mineral volume changes is calculated. The first batch modelling studies with $\mathrm{CO}_{2}$ were published by Gunter et al. (1997). Gaus et al. (2004) presented a long-term batch geochemical study of two natural $\mathrm{CO}_{2}$ analogues at Montmiral (France) and Messokampos (Greece) using the PHREEQC code developed by the USGS (Parkhurst and Appelo, 1999). At Montmiral, it was shown that the $3.8 \%$ porosity increase that can possibly be attributed to $\mathrm{CO}_{2}$ related reactivity requires that sediments have been flushed intensively with $\mathrm{CO}_{2}$ rich-pore waters (open system) and that a flow regime in the reservoir must have been in place at a certain point in the reservoir's geological history. Pruess et al. (2001) and $\mathrm{Xu}$ et al. (2004) have presented long-term batch geochemical modelling of mineral trapping in deep aquifers through carbonate mineral precipitation.

Reactive transport modelling - Batch geochemical modelling is ideal when modelling laboratory batch experiments. However, it becomes limited when considering injection of $\mathrm{CO}_{2}$ in a geological storage formation as hydrodynamics play a dominant role in the different trapping processes. TOUGHREACT is an enhancement of the multi-phase fluid and heat flow code TOUGH2 to reactive transport (Xu and Pruess, 2001). Its last version (Xu et al., 2006), is able to model supercritical $\mathrm{CO}_{2}$ injection in a reservoir by considering hydraulic processes, thermal variations and chemical phenomena. Both dissolution and precipitation processes are integrated in this code with a retro-action on porosity and permeability. Considering a two phase system (supercritical $\mathrm{CO}_{2}$ and brines), $\mathrm{Xu}$ et al. (2005) simulated with TOUGHREACT a $1 \mathrm{D}$ vertical reactive transport model considering $\mathrm{CO}_{2}$ geologic storage within a sandstoneshale system. The very detailed mineralogical assemblage used in the study is representative of Texas Gulf Coast sediments. Xu et al. (2003) presented another 1D horizontal model of $\mathrm{CO}_{2}$ injection in deep arenaceous formations of U.S. Gulf Coast. In this case, the mesh geometry is radial with one layer and with a constant porosity and permeability field. A detailed mineralogy was selected representative of the Gulf Coast formations. Porosity modification due to simulated chemical reactivity was estimated for residence times of up to 10000 years. André et al. (2007) have used TOUGHREACT to simulate fluid rock interactions during $\mathrm{CO}_{2}$ injection for dry out effects. They simulated complete liquid phase vaporization near the well where the salinity and overall mineralisation of the brine (high ionic strengths) becomes very high so that conventional geochemical models become unsuitable. Other models, next to the TOUGH family, that are capable of incorporating these conditions are the SIMUSCOPP code (Institut Français du Pétrole - France) and the STOMP code (Pacific Northwest National Laboratory - PNNL - USA) as pointed out in Pruess et al. 
(2002). Obi et al. (2006) have presented a 3D model of $\mathrm{CO}_{2}$ storage into a deep North Sea aquifer using streamline-based simulation using a rate-limited precipitation reaction. Lagneau et al. (2005) have simulated the injection of $\mathrm{CO}_{2}$ injection into the Dogger (Paris Basin) deep saline aquifer using the reactive transport code HYTEC which does not consider two-phase flow and therefore only the dissolved part of the injected carbon dioxide is simulated. Johnson et al. (2001) have simulated for a period of 20 years with 10 years of $\mathrm{CO}_{2}$ injection at Sleipner, North Sea. They developed a software package based on NUFT for the reactive transport part, and SUPCRT92 and GEMBOCHS for the geochemical and thermodynamics/kinetic databases (Nitao, 1998; Johnson et al., 1992; Shock, 1998, Johnson and Lundeen, 1994). In a similar approach, Audigane et al. (2006, 2007(a)) have presented a $2 \mathrm{D}$ axial model to simulate $\mathrm{CO}_{2}$ injection at Sleipner using TOUGHREACT. In further work Audigane et al. (2007(b)) modeled two 3D models of the $\mathrm{CO}_{2}$ injection at the depleted gas reservoir field $\mathrm{K} 12 \mathrm{~B}$, North Sea. One model is performed with TOUGHREACT considering the gas phase as pure $\mathrm{CO}_{2}$, and the second model is performed using TOUGH2/EOS7C taking into account the $\mathrm{CO}_{2} / \mathrm{CH}_{4}$ mixture but without any geochemical reactivity. White et al. (2001) and (2005) have developed the reactive transport code CHEMTOUGH which is another adaptation of TOUGH2 for reactive transport modelling using a fully coupled approach for solving hydrodynamics and geochemical reactivity equations (Yeh and Tripathi, 1991). Nghiem et al. (2004) have developed and used the commercial code GEM-GHG which is a combination of a black oil simulator and a geochemical batch code to present 1D, 2D and 3D model considering convective and dispersive flows, as well as calculating phase equilibrium for reactions between the oil, gas and aqueous phases, and chemical equilibrium and kinetic dissolution and precipitation reactions between minerals. A specific method for solving simultaneously fluid flow and geochemical equations is presented. In one of the rare papers considering the injected $\mathrm{CO}_{2}$ stream does not consist of $\mathrm{CO}_{2}$ for $100 \%$, Ozah et al. (2005) modeled the injection of a gas mixture consisting of $\mathrm{CO}_{2}$ and $\mathrm{H}_{2} \mathrm{~S}$, while Knauss et al. (2005) and $\mathrm{Xu}$ et al. (2007) evaluated the impact of co-injecting $\mathrm{H}_{2} \mathrm{~S}$ and $\mathrm{SO}_{2}$.

\section{Reliability and the integration of geochemical modelling data}

While modelling codes are increasingly capable of incorporating specific geochemical interactions caused by $\mathrm{CO}_{2}$ and calculation efficiencies continue to improve, the underlying data and their conceptualisation will ultimately determine the quality of the model outcomes. This is where solute transport modelling differs significantly from pure flow or dynamic 
modelling, when modelling the $\mathrm{CO}_{2}$ behaviour. Decades of reservoir modelling helped to optimise data acquisition in the field and steering experimental programmes that ultimately resulted in well constrained reservoir models with a large predictability that can now be used for modelling $\mathrm{CO}_{2}$ storage with relatively minor adaptations. Furthermore, some of the data acquisition techniques, such as the seismics, that is capable of monitoring supercritical $\mathrm{CO}_{2}$ plumes (Chadwick et al., 2006) now prove extremely useful for constraining dynamic $\mathrm{CO}_{2}$ flow models. These techniques also improve large scale solute transport models, but on top of that, the characterisation of the chemical aspects of the coupled model requires access to various types of data that are outside the domain of classic reservoir modelling and that have never been evaluated neither acquired in a similar context. Especially at large depths and high temperatures acquiring detailed data on the mineralogy of the rocks and their heterogeneity and on the chemical composition of the brines remain extremely difficult. Furthermore very little experiments characterising geochemical interactions have been performed under these high P-T conditions and in the presence of $\mathrm{CO}_{2}$ (Rochelle et al., 2004; Bateman et al., 2005 and Kazuba et al., 2005 being rare examples). This gap in experimental knowledge that would allow the characterisation of basic parameters of $\mathrm{CO}_{2}$ rock interactions remains a weak spot and affects the reliability of solute transport modelling considerably (see further). At the present time, reactive transport simulations do not consider any direct geochemical interactions between dry $\mathrm{CO}_{2}$ (gaseous and supercritical) and minerals though laboratory experiments have demonstrated a strong chemical reactivity between these components especially for minerals constituting well cements (Jacquemet et al., accepted; Jacquemet, 2006 and Regnault et al., 2005).

In the following paragraphs, the data required for characterising geochemical reactions that need to be fed into the geochemical and coupled models are discussed. Data required for performing the dynamic flow part of the coupled models (eg relative permeabilities, capillary pressures) are discussed elsewhere (Juanes et al., 2006).

\subsection{Properties of $\mathrm{CO}_{2}$}

When modelling the injection of $\mathrm{CO}_{2}$ into saline water, the physical and physico-chemical properties (density, solubility, viscosity and enthalpy) of the $\mathrm{CO}_{2}$-brine system must be included in the solute transport model. For example, the effect of $\mathrm{CO}_{2}$ dissolved in brine and $\mathrm{H}_{2} \mathrm{O}$ dissolved in gas on the properties of both phases cannot be neglected for accurate modelling since the $\mathrm{CO}_{2}$ dissolution will raise the brine's density in such a way that density 
driven convective flow can be induced. A large number of equations of state (EOS), describing these properties, are currently available. But only a few indicate an accurate value for a large range of temperatures and pressures, including the discontinuity along the gasliquid phase change line. The Duan et al (1992) equation of state is one of the most advanced and covers the whole pressure and temperature domain relevant for $\mathrm{CO}_{2}$ storage applications, (Figure 4; example shown for $\mathrm{CO}_{2}$ density), but at the price of numerical complexity. Most coupled models therefore incorporated generally an EOS valid only within a targeted range.

Figure 4. $\mathrm{CO}_{2}$ density as a function of temperature and pressure based on the equation of state (EOS) from Duan et al (1992).

These equations are also used to calculate the fugacity of the $\mathrm{CO}_{2}$ which determine its solubility, in conjunction with an aqueous model that will account for the salting out effect (Figure 5).

Figure 5. Concentration of dissolved $\mathrm{CO}_{2}$ (in mol per $\mathrm{kg}$ water) as a function of temperature and pressure in pure water (left) and in a $200 \mathrm{~g} / \mathrm{l}$ brine (right) as derived from the Duan and Sun (2003) model.

Furthermore for correct chemical modelling of brines with high salinities the Pitzer formalism (Pitzer 1973, 1991) should be applied to accurately describe these aqueous solutions. The Pitzer formalism is currently seldom applied in geochemical codes and rarely in solute transport codes (as in Zhang et al., 2005). Generally, ion association models such as DebyeHuckel, Davies, b-dot models, suitable for dilute solutions only are applied. Figure 6 shows the dissolution of the carbonate calcite and highlights the error induced by the use of model only suited for dilute solutions (Davies, b-dot). This figure also shows that at high $\mathrm{pCO}_{2}$, even in pure water, the $\mathrm{CO}_{2}-\mathrm{HCO}_{3}{ }^{-}-\mathrm{Ca}^{++}-\mathrm{H}^{+}$system behaviour is not well calculated with such models (although temperature correction might also play a role).

Figure 6 Amount of calcite dissolved in $\mathrm{NaCl}$ solutions at $60^{\circ} \mathrm{C}$ under a $\mathrm{pCO}_{2}$ of 100 bar calculated with different formalisms (Pitzer, Davies, b-dot).

Kervévan et al. (2005) summarized the relative weight of the different corrections that must be applied to the calculation of $\mathrm{CO}_{2}$ solubility and mineral equilibrium. This showed that the 
corrections with respect to the fugacity and the salting out effect are the most important for $\mathrm{CO}_{2}$ solubility calculation, while an adequate aqueous model is necessary for water rock interactions modelling. Unfortunately, this approach is numerically less efficient and there is a lack of data concerning the behaviour of some chemical elements, especially at high temperature. For the time being, only few thermal-hydraulic-chemical codes use this chemical approach, even if some codes are under development (Zhang et al., 2005; 2006).

While the required models exist for the $\mathrm{CO}_{2}$-brine system, there is currently an important absence of data for the integration of other gaseous compounds in the gas phase, that might be co-injected (eg $\mathrm{O}_{2}, \mathrm{~N}_{2}, \mathrm{NO}, \mathrm{SO}_{2}$ ), beyond the broad assumption of ideal mixing.

\subsection{Selection of mineralogical compositions and their thermodynamic characteristics}

Access to detailed mineralogical data when assessing the impact of geochemical reactions is crucial, and the selection of the primary and secondary mineral assemblages is critical in this type of simulations (Zhu and Burden, 2001). Even detailed mineralogical descriptions of a rock do not permit a unique and straightforward description in the geochemical model since the exact molecular composition has to be entered and the thermodynamic constants must be known. Especially in the case of solid solutions or clay minerals, where exact composition and thermodynamic properties are seldom sufficiently known, this proves difficult. An example of the impact of selecting different compositions of a plagioclase solid solution is described in Gaus et al. (2005). The selection of the secondary minerals is no less delicate. Secondary minerals are minerals which precipitate as a consequence of geochemical reactions caused by $\mathrm{CO}_{2}$ and which are not present initially. A pragmatic way of selecting secondary minerals for the kinetic modelling is checking which minerals tend to be supersaturated when assuming thermodynamic equilibrium conditions. But it cannot be excluded that intermediate minerals may form which can re-dissolve in the course of time (metastable equilibria) to precipitate as more stable minerals once the final equilibrium is reached. Furthermore, secondary mineral assemblages are seldom unique. Different choices, especially with respect to alumino-silicate minerals, might meet the criteria mentioned above, but might lead to different results. Certain minerals assumed to be capable of trapping $\mathrm{CO}_{2}$, such as dawsonite, are included in many models but have only very recently been characterised (Carey et al., 2006; Bénézeth et al., 2007) and it remains unsure if they will function as a carbon trap in real 
cases (Hellevang et al., 2005). Furthermore, only in some cases complex heterogeneous mineral distributions can be represented by average mineral properties to simplify reactive transport calculations (Glassley et al., 2002), although assuming average mineral properties is currently common practice because of computational limitations.

\subsection{Kinetic data and rate laws}

When modelling geochemical reactions for $\mathrm{CO}_{2}$ storage purposes, reaction kinetics generally have to be included in order to obtain a reliable outcome (Gaus et al., 2005). Reaction kinetics varies over a large range depending on the type of reaction. Some reactions can be extremely slow, comparable to the geological scale, while other reactions reach equilibrium conditions after a couple of hours or even less. To model the evolution of the geochemical system in time, one needs to know all the factors controlling the reaction mechanisms and their rates. Accurate data on these processes are very difficult to acquire for complex systems. However, in some cases simplifications can be made, so that instantaneous equilibrium can prove a reasonable assumption. Typically, the study of complex system starts with a thermodynamic model at the equilibrium state. This highlights the occurrence of potential dominant reactions occurring. Subsequently precipitation and dissolution kinetic rates are introduced into the model, in order to model the evolution of the system in time and to describe the reaction pathways in detail. However, model results depend on the kinetic laws used and on parameters (typically "lumped parameters" representing more than one process) feeding into these laws that are not well-known, especially for the conditions relevant to $\mathrm{CO}_{2}$ storage.

Many kinetic laws are described in the literature (Plummer et al. 1978; Pokrovsky et al. 2005; Lasaga et al. 1994). The kinetic law mostly used in geochemical modelling applied to the storage of $\mathrm{CO}_{2}$ is a simplified law from Lasaga et al. (1984) considering that for many minerals the kinetic rates can be summed from three mechanisms: neutral $(\mathrm{nu})$, acidic $(\mathrm{H})$ and basic (b) (Lasaga et al., 1984; Palandri et Kharaka, 2004):

$r_{m}= \pm A_{m}\left(k_{T}^{n u}+k_{T}^{H} a_{H}^{n_{H}}+k_{T}^{b} a_{b}^{n_{b}}\right)(1-Q / K)$

Where $\mathrm{r}$, is the dissolution rate, $A_{m}$ is the reactive surface area, $\mathrm{a}_{\mathrm{H}}$ is the proton activity, $\mathrm{a}_{\mathrm{b}}$ is the base activity, $\mathrm{n}_{\mathrm{H}}$ and $\mathrm{n}_{\mathrm{b}}$ the power for the acid and base activity, $\mathrm{Q}$ is the ionic activity product, $\mathrm{K}$ is the equilibrium constant. The basic mechanism depends on activities of the ions 
$\mathrm{H}^{+}$or $\mathrm{OH}^{-}$according to the applied law or on the $\mathrm{CO}_{2}$ pressure or carbonates activities for carbonate minerals. The largest effect of $\mathrm{CO}_{2}$ on the dissolution rates is for carbonate minerals. The activities of the ions $\mathrm{H}^{+}$and if included also $\mathrm{OH}^{-}$and $\mathrm{P}_{\mathrm{CO} 2}$ associated with $k^{H}$ or $k^{b}$ are usually raised to the power of one $\left(n_{H}=n_{b}=1\right)$, but other values have been observed experimentally, especially at ambient temperatures (Palandri et Kharaka, 2004; Chou et al. 1989). All three mechanisms are rarely included in geochemical modelling applied to $\mathrm{CO}_{2}$ storage (exceptions are Xu et al. 2006; André et al. 2007) especially because pH environments for $\mathrm{CO}_{2}$ storage environments are generally assumed to be acidic due to the dissolution of $\mathrm{CO}_{2}$. Some authors consider only the neutral mechanism (White et al. 2005; Zerai et al. 2006) or the acidic mechanism (Gaus et al. 2005; Lagneau et al. 2005) while some others consider both neutral and acidic mechanisms (Xu et al. 2005; Gunter et al. 2000). Until now, the almost complete absence of experimental precipitation rate in the literature has led to the fact that precipitation rates are set equal to dissolution rates in coupled models although it is demonstrated that the precipitation rates of some minerals such as alteration minerals can be slow. Minerals do not immediately crystallize out of supersaturated solution even in the presence of nucleation seeds (Lasaga et al. 1994).

Dissolution rate data are available from a variety of sources reporting kinetic rate constants (a recent compilation is made in Palandri and Kharaka (2004)). The constants are measured at various temperatures, pressures and $\mathrm{CO}_{2}$ partial pressures and for brine composition different than those generally applicable to a $\mathrm{CO}_{2}$ storage context. These conditions have an important impact on the rate itself as demonstrated for the $\mathrm{CO}_{2}$ sensitive mineral labradorite in Carroll and Knauss (2005). Consequently, geochemical modellers do not use the same experimental values for the kinetic rates or for the $\mathrm{n}_{\mathrm{H}}$ values (Xu et al. 2005; Gunter et al. 2000; Gaus et al. 2005). To illustrate this variability in dissolution rates used for geochemical modelling a comparison is made for three minerals (dolomite, kaolinite and albite) that usually dissolve and/or precipitate as a consequence of $\mathrm{CO}_{2}$ induced interactions (Figure 7). For dolomite, the variability can be attributed to the description of the acid mechanism. The modelled dissolution in the neutral and basic range are similar and correspond to the experimental data and model of Chou et al. (1989), except for two authors who used dissolution rates of other minerals than dolomite as a proxy (Xu et al. 2005, White et al., 2000). The range for kaolinite is much larger; due to the large variability in experimental dissolution rates: from $10^{-13.7}$ to $10^{-}$ 11.6 (in mol $/ \mathrm{m}^{2} / \mathrm{s}$ ) at $\mathrm{pH} 3$ (Huertas et al. 1999; Metz et Ganor 2001). For albite, the dissolution is controlled by the $\mathrm{pH}$ dependency both in an acidic and basic environment (Chou and 
Wollast, 1985). Although this comparison does not take account for the impact of the surface area - that is likely to be different for different media-, it clearly illustrates for one mineral the dissolution rate in the models can vary between 1 to 3 orders of magnitudes, all based on reasonable assumptions. This obviously has an impact on the modelled results as also illustrated in the following paragraphs.

Figure 7. Comparison of modelled dissolution rates for dolomite, kaolinite and albite at $25^{\circ} \mathrm{C}$ based on Palandri and Kharaka (2004), Gunter et al. (2000), Xu et al. (2005), Chou et al. (1989), White et al. (2000), Gaus et al. (2005).

A further complicating factor when introducing kinetics is the estimation of the reactive surface area of the dissolving minerals since the dissolution rate depends on the available surface area in contact with the aqueous solution. The BET method is most used for measuring the total surface area of a mineral. However, interaction with the minerals is generally expected to occur only at selective sites at the surface (also due to the presence of grain coatings) and the difference between total surface area and reactive surface area can be between 1 and 3 orders of magnitude (White and Peterson, 1990). An alternative method to estimate the surface of the minerals, since BET measurements are only available on rare occasions, is based on the theoretical geometric surface area using average grain diameters (ranging from 1 to $200 \mu \mathrm{m}$ (Gunter et al. 1997; Zerai et al. 2006)). This method generally underestimates the real reactive surface area since particle surfaces are rough, disrupted and porous.

The fact that in the general kinetic law the product of the reactive surface area with the kinetic rate constant is incorporated, and that both parameters are difficult to characterise, explains the large uncertainty on the results of geochemical and coupled models once reaction kinetics is included.

\section{Main applications for geochemical and solute transport modelling (state of the art and future work)}

\subsection{Long term integrity applications}

Some of the first and most successful applications of coupled modelling for $\mathrm{CO}_{2}$ storage purposes are the long term integrity applications: medium or long term coupled models that 
take into account the geometry of the reservoir (and sometimes also the caprock) in a simplified way, and predict the ultimate fate of the injected $\mathrm{CO}_{2}$. Especially during the last couple of years, with codes becoming more adapted, several studies appeared either in including one dimensional (Knauss et al., 2005; Xu et al., 2005), two dimensional (Audigane et al., 2007(a); Johnsson et al., 2001; White et al., 2005) or three dimensional (Nghiem et al., 2004; Le Gallo et al., 2006) transport. When geometries remain simple, it is still possible to identify dominant geochemical interactions from the calculated species concentrations and amounts of minerals dissolving and precipitating. However, when the geometric complexity of the model grid and the number of layers increase, such as is the case in White et al. (2005), the identification of dominant geochemical reactions becomes increasingly difficult and the calculated results has to be accepted without being able to distil the individual geochemical reactions. In this work, a $2 \mathrm{D}$ vertical reactive transport model of $\mathrm{CO}_{2}$ injection in saline reservoirs of the Colorado Plateau was developed that considers time periods of up to 100000 years with two different meshes. A very detailed model of the hydrology of the Colorado plateau was simulated on a fine grid mesh without performing geochemistry simulations. The second mesh is coarser to provide a reactive transport simulation including complete mineralogy with plagioclase, K-feldspar, dolomite, quartz, mixed clays, illite, iron minerals and calcite. These long term integrity models ultimately led to the consensus over the long term behaviour as already represented in Figure 2.

However, where different codes were applied for similar cases, results might seem not complementary or even contradictory with respect to certain conclusions on the long term behaviour. A clear example is the solute transport modelling performed based on the conceptual data from the Sleipner case, the first and therefore best documented saline aquifer storage case. At Sleipner $\mathrm{CO}_{2}$ is injected into the Mio-Pliocene Utsira Sand since 1997. Repeat seismic surveys have shown that the injected $\mathrm{CO} 2$ moves, due to buoyancy effects, upward from the injection point and accumulates under the overlying cap rock (Torp and Gale, 2002). This is also confirmed by reservoir simulations which predict that $\mathrm{CO}_{2}$ should reach the base of the thick shale layer close to the top of the Utsira Sand approximately three years after injection (Lindeberg et al., 2000). In order to assess the geochemical impact of this operation, Johnson et al. (2001) perform calculations over 20 years with 10 years of $\mathrm{CO}_{2}$ injection using three conceptual 2D coupled models including the aquifer and its caprock. Some heterogeneity of the permeable sand aquifer is introduced through the presence of semi permeable shale layers. The density difference due to $\mathrm{CO}_{2}$ dissolution in the brine causing 
convective flow patterns is not considered in the model, neither are the $\mathrm{CO}_{2}$ dissolution pressure and temperature dependencies. This geometry resembles the 2D radial model published by Audigane et al. (2006, 2007(a)) that does not include the caprock. This paper presents a long term simulation highlighting the impact of the convective flows inducing the acceleration of the dissolution and the geochemical reactivity associated using different mineralogies for the sand and intercalating shale layers. Frangeul et al. (2005) simulate $\mathrm{CO}_{2}$ injection with convective flow in the Utsira Sands in 3D using the detailed flow modelling grid presented in Lindeberg et al. (2000) with a simplified mineral assemblage containing only carbonates (calcite and dolomite). In a follow up paper, Thibeau and Nghiem (2007) extend the number of minerals included and perform calculations using the same model but on a coarser grid. A limited sensitivity analysis on the picking of the minerals in the models to represent the reservoir mineralogy is performed. Gaus et al. (2004) model the interactions in the caprock only using a one dimensional aqueous model. Diffusion of $\mathrm{CO}_{2}$ through the rock is modeled by Henry's law with a constant fugacity coefficient. An overview of the coupled flow geochemical models that refer to the Sleipner case as well as their main conclusions are given in Table 1.

Table 1. Overview of published solute transport models that refer to the Utsira saline aquifer storage case at the Sleipner site, their main characteristics and findings.

Although some of these results might seem contradictory, these papers show results of different modelling scenarios all referring to the same case but based on slightly different assumptions or including different parameter values. For example in the Frangeul et al. (2005) simulation only carbonate minerals are included. This simplification prevents any mineral trapping to be calculated because pure carbonate minerals are not capable of acting as iprimary minerals for the trapping of $\mathrm{CO}_{2}$. Indeed, mineral trapping can only occur through the dissolution of cation donor minerals (eg feldspars). A complete mineralogical description is included in Thibeau and Nghiem (2007), confirming that mineral trapping can become important and that the selection of the minerals in the model based on the mineralogical analysis from the rock is crucial. A composition based on mica's consisting predominantly of annite (an iron rich biotite) and feldspars consisting of anorthite (a calcium rich feldspar) proves far more reactive than other mineral combinations. This illustrates the need for accurate mineralogical descriptions when performing these calculations. The fact that the modelled porosity reduction in the caprock in Johnsson et al. (2001) seems more important 
after 20 years than the porosity reduction after 3000 years calculated in Gaus et al. (2004) can entirely be attributed to the fact that both authors use different parameters values for the specific surface areas of the minerals. This parameter determines directly the rate at which reactions occur and is extremely difficult to measure or to estimate (paragraph §5.2). The specific surface areas used in the two papers span the range of reasonably acceptable values. The only difference between the results for the porosity reduction in the caprock is the rate at which the reactions occur, not the type of the reaction or the impact on the porosity as such. Finally, the fact that in Audigane et al. $(2006,2007(\mathrm{a}))$ the bulk of the injected $\mathrm{CO}_{2}$ seems to be dissolved is related to the length of the simulation (10000 years) and the fact that heterogeneities (shale layers) are taken into account. These encourage the dissolution because the $\mathrm{SC}-\mathrm{CO}_{2}$ is spread out over a larger area.

The main message to retain from the 5 publications is that for $\mathrm{CO}_{2}$ storage in the Utsira formation at Sleipner, hydrodynamic trapping will be the dominant trapping mechanism in the aquifer for a long time, mineral trapping is less important apart from the very long term, but even then only will have a small impact on the porosity of the aquifer, that the intra-aquifer shales (and heterogeneities in general) aid the spreading of the SC-CO2 and thus the dissolution process and that the integrity of the caprock is unlikely to be affected when no SC$\mathrm{CO}_{2}$ enters the caprock. At this more general level, the results of the papers reinforce each other rather than contradict.

The long term integrity studies for which coupled models are used based on large grids representing the reservoir and caprock geometry have reached a point where the uncertainties affecting the modelled results are predominantly caused by the chemical parameters of the model such as the mineral selection, their kinetics and the reactive surface area.

\subsection{Near well applications, impacts on injectivity}

$\mathrm{CO}_{2}$ injection for geological storage is a process that will take a couple of decades per site. That implies a good knowledge of the reservoir and processes sensed to occur in the vicinity of the injection well during the injection phase is necessary. A massive injection of million tons per year can involve thermal, hydraulic, mechanical but also chemical perturbations around the open-hole section of the injection well. Coupled thermal-hydraulic-chemical 
(THC) codes reproduce many of these processes and interactions between them and can aid injectivity forecasts. Although guaranteeing the injectivity is a key to the viability of a $\mathrm{CO} 2$ storage project, very little has been published on this topic so far. TOUGHREACT (Xu et al., 2006) was applied to study the behaviour of the near well during supercritical $\mathrm{CO}_{2}$ injection (André et al, 2007). The results demonstrated that chemical processes vary according to the distance from injection well (Figure 8). Initially, after injection started, $\mathrm{CO}_{2}$ dissolves in the brine initially present within the reservoir and changes its chemical composition (Figure 8, zone 2). The $\mathrm{pH}$ of the brine decreases and reaches 4.9-5.0, buffered by the dissolution of carbonate minerals present in the host rock. This dissolution process can, if the formed porosity is connected, improve the injectivity index of the well. However, during a long-term injection, the acidification phase is followed by a desiccation phase. $\mathrm{A}^{\mathrm{CO}_{2}}$ gas bubble forms around the injector pushing original water away far from the injection well (Figure 8). Within the bubble, the medium is totally desiccated due to the absorption of residual water by the flow of the $\mathrm{CO}_{2}$-rich dry phase. As a consequence, zone 2, initially near the injection well moves further away within the reservoir. The formed dry zone, centred round the injector (zone 5), constitutes a favourable site for gas-mineral interactions as demonstrated experimentally by Regnault et al. (2005). Between zone 5 (gas saturation $=1$ ) and zone 2 (gas saturation $=0$ ), two other zones can be distinguished. Zone 4 presents very low water saturations (Figure 8). Brine trapped in micro pores evaporates through the continuous dry $\mathrm{CO}_{2}$ flow leading to the precipitation of certain secondary minerals (such as salts). This scaling process is highlighted by experimental data (Kaszuba et al., 2003; Rosenbauer et al., 2005). In case of $\mathrm{CO}_{2}$ injection, this phenomenon is to be considered: salts precipitation in the near vicinity of the injector can induce a decrease in porosity and consequently in well injectivity (André et al, 2007). This effect is salinity-dependent and it will be more pronounced in the case of high salinity brines. Within zone 3, the multiphase system is in equilibrium and the presence of acidified water tends to favour mineral dissolution and porosity increase.

Figure 8. Conceptual diagram of the reactive zones around the injection well as derived fro coupled modelling (Azaroual et al., 2007). The different radii $\left(r_{1}, r_{2}, r_{3}, r_{4}\right)$ are dependent on $\mathrm{CO}_{2}$ injection flow rate and rock properties.

Although THC codes present many advantages to forecast injection flow rates or chemical processes, improvements are still necessary to describe the vicinity of the injection well in a 
correct way. Other parameters need to be integrated within modelling to increase the knowledge of this zone.

- All THC codes carry out the feedback of chemical variations on porosity and permeability. But, a good description of the porous structure to describe its evolution according to injected volume, flow rates and chemical perturbations is needed. The porosity/permeability relationship constitutes a major parameter, which will be type reservoir-dependent.

- THC codes only consider interactions between minerals and aqueous phases. But, Regnault et al. (2005) demonstrated that mineral changes are expected in presence of pure $\mathrm{CO}_{2}$ phase (as transformation gypsum-anhydrite). THC codes will have to integrate the reactivity of supercritical $\mathrm{CO}_{2}$ with minerals. This development is particularly important for the near well, where supercritical $\mathrm{CO}_{2}$ saturation is close to one.

- To deal with saline brines, the Pitzer formalism should be applied (Pitzer, 1973; Pitzer, 1991) but codes including this approach are still under development (Zhang et al., 2006). Consequently, with actual code versions, some approximation and under-estimations are likely particularly in the near well environment where the presence of high salinity brines is expected during the desiccation processes (Andre et al, 2007).

At last, THC codes do not integrate the mechanical deformation involved by $\mathrm{CO}_{2}$ injection. For the time being, fully coupled Thermal-Hydraulic-Chemical-Mechanical codes are still in the development stage. The first simulations, with external coupling between the reactive transport model and geomechanical model, give encouraging results. Rudqvist et al. (2006) modelled multi-layer systems using a coupling between TOUGH2 and FLAC3D (Itasca, 1997) whereas Le Gallo et al. (2006) presented the long-term impact of $\mathrm{CO}_{2}$ injection into a saline aquifer using the reactive transport model COORES and the geomechanical model ABAQUS. However, these applications concern large scale modelling and efforts have now to be concentrated on the near well environment.

\subsection{Geochemical modelling and well integrity}

To date, few studies deal explicitly with well cement degradation modelling for $\mathrm{CO}_{2}$ storage applications. However, cement chemical degradation has been modelled many times to evaluate the material's durability in a context of nuclear waste containment (e.g. De Windt et 
al., 2004; Yokozeki et al., 2004; Trotignon et al., 2006). One of the main differences between both is that while the first requires modelling at a low, acidic $\mathrm{pH}$ values, the latter generally takes place at high, basic $\mathrm{pH}$ values generating different geochemical reactions. In the few studies where cement degradation is modelled for $\mathrm{CO}_{2}$ storage purposes, this occurs using 1 dimension only without including the geometry of the well itself (Jacquemet, 2006; Carey and Lichtner, 2007 and Carey et al., 2007). While simulations performed by Jacquemet (2006) had the purpose of reproducing experiments, Carey and Lichtner (2007) and Carey et al. (2007) aimed to reproduce field sample degradation. Two further studies, although executed in a nuclear waste context, are further worth mentioning: Pfingsten (2002) and Burnol et al. (2006). Their work is applicable to $\mathrm{CO}_{2}$ storage since they also modelled carbonation of cement. However these authors did not constrain their simulations by experimental or field observations.

All the models have the same overall constructions and features:

- one dimensional models (except Pfingsten (2002) which performed two dimensional simulations) where a homogeneous cement domain is adjacent to an external media with sharp carbon concentration and $\mathrm{pH}$ gradients between the two domains (Table 2),

- a fully water-saturated cement domain (except in Burnol et al (2006) where the cement domain is initially filled with water and gas, Table 2),

- transport of chemical species dominated by molecular diffusion.

In Carey and Lichtner (2007) and Carey et al. (2007), the external media is composed of a clayey rock while it is composed of brine only in Pfingsten (2002) and Jacquemet (2006). The simulated P-T conditions vary from room conditions to 500 bar- $200^{\circ} \mathrm{C}$ and the cement domain lengths range from $1.510^{-3} \mathrm{~m}$ to $2 \mathrm{~m}$.

Table 2. Characteristics of the cement/ $\mathrm{CO}_{2}$ interaction modelling studies.

In all the models, $\mathrm{CO}_{2}$ and $\mathrm{H}^{+}$diffusive fluxes occur from the external media through the cement, driven by the chemical gradients, and carbonation occurs. In Burnol et al. (2006), Carey and Lichtner (2007) and Carey et al. (2007), a carbonated rim (exhibiting an assemblage of carbonates plus secondary minerals) of cement is modelled (Figure 9). Burnol et al. (2006) report also a decrease of porosity associated with this carbonated rim. In Pfingsten (2002) and Jacquemet (2006), the carbonation front is mimicked by a rim of 
decalcified cement (exhibiting Ca-depleted CSH) and a separate calcite coating at the surface of the cement (Figure 9). As this coating grows, it becomes a barrier (porosity close to zero) for the incoming species (carbonates and protons) and blocks the degradation of the cement. The calcite coating can develop due to the available volume at the surface of cement that allows calcite to precipitate. This is in contrast to the three other studies where the external media is made of rock where no such available volume allows calcite to massively precipitate.

Figure 9. Conceptualisation of carbonation fronts of cement based on five modelling studies.

Various research needs are identified by the authors in order to better constrain cement degradation modelling: 1) improved transport parameter characterization (diffusivity and permeability) of well cements; 2) improved determination of thermo-kinetic parameters of well cement minerals reactions at appropriate P-T conditions; 3) evaluation of the impact of cement heterogeneity. Pfingsten (2002) also emphasizes the need for additional data on the dependence of permeability and diffusivity on porosity since carbonation is likely to decrease porosity significantly (Thiery, 2005; Jacquemet, 2006). As it was explored by Burnol et al. (2006), future modelling should take into account the possibility of carbonation in two-phase conditions, e.g. by intrusion of gas within the cement. Regnault (2005) and Jacquemet (2006) demonstrate experimentally that significant carbonation can also occur in the complete absence of brine. As mentioned before, currently reactive-transport codes do not consider gasmineral reactions and should in the future. For cements, carbonation is responsible of shrinkage (Taylor, 1997; Kovler and Zhutovsky, 2006). Coupling geochemical and mechanical models could help to better understand mechanical effects of carbonation. Other reactions between other gaseous components and cement should also be taken into account. For example, $\mathrm{SO}_{2}$ and $\mathrm{SO}_{3}$ could potentially be co-injected with $\mathrm{CO}_{2}$. These gases will form dissolved sulphates $\left(\mathrm{HSO}_{4}{ }^{-}, \mathrm{SO}_{4}{ }^{2-}\right)$ within formation water (under specific conditions) that are known to damage cement via the "sulphate attack" reaction. This has important deleterious physical effects like internal cracking and expansion (Taylor, 1997; Maltais et al. 2004). Carey and Lichtner (2007) modelled a sulphate attack reaction of a well cement. They reproduced the general mineral changes related to this reaction (i.e. precipitation of sulphates (ettringite, gypsum) and decalcification of $\mathrm{CSH}$ ).

Finally, the existing studies account for relatively small scale systems at the laboratory scale (Table 2) not taking into account the geometry of the cement sheath or the well . After up- 
scaling, the final goal of future well cement modelling degradation would be the prediction of $\mathrm{CO}_{2}$ vertical flux through the cement sheath.

6.4 Calibration and validation of the geochemical and solute transport models on laboratory and field experiments

Most of the phenomena and their impact predicted by geochemical and coupled models run over long time frames (long term integrity modelling, injectivity modelling). For these timeframes, calibration is generally not possible since multiple year time-series with data on geochemical impact plainly do not exist. Therefore only laboratory experiments and small scale field studies can be used as an alternative for calibration and to verify that processes predicted by the long term models are occurring in reality. The major drawback remains that these experiments can run at best over a couple of years and are thus not capable of reproducing slow phenomena that have an impact on the long term only, especially when conducted at low temperatures $\left(<60^{\circ} \mathrm{C}\right)$.

A series of experiments have been conducted and modelled to assess the mineral trapping capacity and porosity changes in porous media. Gunter et al. (1997) carried out batch experiments containing a mineral assemblage that reacts with $\mathrm{CO}_{2}$ rich solution $\left(105^{\circ} \mathrm{C}\right.$ and 90 bars). Due to slow reaction rates, the transformation of alumino-silicates is not observed but the composition of the solution changes. The geochemical model (PATHARC94) helps to interpret these data, but the authors highlight potential errors as high as two orders of magnitude using reported kinetic rates which they compensated by reduced the surface area to match experimental and modeled results. In the long term, trapping of $\mathrm{CO}_{2}$ as calcite and siderite occurs, but to understand the processes more detail is necessary on the precipitation kinetics and the exact composition of the mineral phases (solid solution). Batch and column experiments on samples of the Midale formation at Weyburn were assessed through thermodynamic equilibrium modeling (Azaroual et al., 2005) illustrating carbonate dissolution, precipitation of gypsum and "inhibition" of anhydrite dissolution. Observations and model interpretations helped to develop hypothesis that were subsequently included in long term 1D PHREEQC modeling. Rosenbauer et al. (2005) carried out batch experiments reacting $\mathrm{CO}_{2}$ with natural and synthetic brines in the presence or absence of limestone and plagioclase-rich arkosic sandstone under reservoir conditions $\left(120^{\circ} \mathrm{C}\right.$ and 300 bars $)$. The 
authors used SOLMINEQ99 (Kharaka et al. 1988) to calculate in situ carbonate species, $\mathrm{pH}$ and the saturation index of individual minerals. The authors concluded that compositional, mineralogical and porosity changes in the aquifer fluid and rock are dependent on initial brine composition especially with respect to dissolved calcium and sulfate concentrations. Palandri et al. (2005) studied the interaction of $\mathrm{CO}_{2}-\mathrm{SO}_{2}$ with hematite under reservoir conditions $\left(150^{\circ} \mathrm{C}\right.$ and 300 bars $)$ and concluded that reactions are kinetically determined resulting in concentrations far from equilibrium and that the precipitation of metastable phases plays an important role. According to the authors, the predictions based on computer simulations are largely confirmed by experimental results. The $\mathrm{CO}_{2}$ and $\mathrm{SO}_{2}$ mixture reduces $\mathrm{Fe}^{\mathrm{III}}$ in hematite and dissolves it as $\mathrm{Fe}^{\mathrm{II}}$ which subsequently precipitates as siderite and pyrite and/or FeS-am. Shiraki and Dunn (2000) examined water rock interaction through core-flooding experiments under reservoir conditions $\left(80^{\circ} \mathrm{C}, 166\right.$ bars $)$. The solution and $\mathrm{CO}_{2}$ are injected into a core sample from the Tensleep Formation in the Oregon oil field. Three major reactions were identified (1) dissolution of dolomite, (2) alteration of K-feldspar to form kaolinite that reduces the permeability, (3) precipitation or dissolution of anhydrite according to the salinity of the injection solution. These reactions are reproduced using the SOLMINEQ88 (Kharaka et al. 1988) code based on speciation and mineral saturation index calculations. Bateman et al. (2005) provided a well-constrained laboratory experiment of long duration whereby a synthetic mineral composition reacts with $\mathrm{CO}_{2}$-rich fluids. The model predictions performed using the coupled code PRECIP tend to overestimate the reactivities compared with the experimental results. Certain minerals phases that are predicted to precipitate in large quantities are not observed in the experimental system. These differences between the model and the observations highlight the need for thermodynamic and kinetic data with respect to $\mathrm{CO}_{2}$ induced interactions at relevant $\mathrm{P}-\mathrm{T}$ conditions, especially with respect to the precipitation of secondary minerals.

The bulk of these experiments have been designed in the first place to observe geochemical interactions and draw conclusions from the observations rather than calibrating coupled geochemical models. This has as a consequence that generally complex mineralogies are selected and that many interacting geochemical reactions occur. This requires many (largely unknown) parameters (such as kinetic constants and reactive surface areas) to be introduced in the models resulting in too many degrees of freedom. Specific experiments could be designed that focus on one or two geochemical reactions, only including a very small number of 
minerals, and that allow for an accurate calibration of the solute transport or geochemical model and the parameters involved.

Experimental work has also been conducted on dissolution of carbonate rocks due to the injection of acids. Dissolution due to the $\mathrm{CO}_{2}$ injection of predominantly carbonates could weaken the injection zone. The difficulty is the modelling of the formation and the propagation of the dissolution patterns (wormholes) which results from an instability similar to viscous fingering. Several authors (Golfier et al., 2001; Pomès et al., 2001) point out the need for developing a numerical code that accounts for wormhole formation at the Darcy scale. Golfier et al. (2001) built a 2D numerical simulator which calculates the dissolution pattern in a core. This code considers the physics at the pore-scale. The flow equation takes into account Darcy flow in the matrix and Stokes law in the wormhole. Based on experimental results, the model provides relations on wormhole propagation rate depending on reservoir properties and injection conditions. It might be possible to integrate these relations in a near well-bore simulator for a better design of the acidizing impacts in carbonates. Pomès et al. (2001) investigate this approach to build the up-scaled model for reservoir simulations.

Small scale field studies that include geochemical monitoring and verification through modelling have been rare so far, the Frio Formation injection (Kharaka et al., 2006) and the Weyburn site (Emberley et al., 2005) being the first. This study clearly demonstrated that reactions that have been predicted by geochemical models before, such as $\mathrm{pH}$ buffering after the dissolution of $\mathrm{CO}_{2}$ through the dissolution of carbonates and dissolution of iron from ironoxides at low pH values, occur in reality. However, also here, the density of the geochemical data and the heterogeneity of the system does not allow for a calibration "sensu strictu" of the geochemical model.

\section{Conclusions and outlook}

Reactive transport modelling is an essential tool for the analysis of coupled physical, chemical and biological processes in earth systems. One of its more recent application domains is that of carbon storage, whereby the impact of geochemical reactions induced by $\mathrm{CO}_{2}$ and its feedback on physical properties has to be assessed. This has to occur at great depth, at high 
temperatures and pressures, conditions that traditionally belong to the domain of reservoir geology, where especially short, medium, and long term geochemical impacts rarely received much attention. During the last 10 years geochemical and coupled geochemical and flow modelling made large progress evolving from simple geochemical batch models to three dimensional fully coupled models. Four main application domains are identified each having a different purpose with respect to analysing the geochemical impact of $\mathrm{CO}_{2}$ storage and each facing its proper challenges.

Long term integrity modelling predicts the final fate of the $\mathrm{CO}_{2}$ injected in terms of structural trapping, residual trapping, solubility trapping and mineral trapping on the reservoir scale. Currently simplified (with respect to classic reservoir models) fully coupled 3D models taking into account a reasonable level of heterogeneity are being developed allowing for such a complex assessment. Weaknesses remain the identification of dominant geochemical reactions (initial mineral selection) and the poor knowledge on reaction kinetics, making it difficult to attribute an adequate timescale to the occurrence of the trapping processes. A further challenge for long term integrity modelling will be making the step from modelling only the reservoir environment toward scenario modelling, that will be part of the risk assessment. Generally, for scenario modelling not only the reservoir has to be taken into account, but also the overburden. In most cases, the overburden is likely to consist of a sequence of cap rocks, saline aquifers and potable aquifers, probably partly cross-cut by faults, fault systems and wells. Including this geological complexity will induce significant numerical difficulties, especially when also geomechanical effects have to be taken into account.

Injectivity modelling assesses the geochemical impact in the direct environment of the borehole, to make sure that injection continues as planned. Coupled modelling in this area thus focuses on a smaller spatial scale (direct borehole environment) and shorter timeframe (injection period) than long term integrity modelling. Here the intense flushing of the reservoir rock around the injector with large quantities of dried $\mathrm{SC}-\mathrm{CO}_{2}$ can cause dessication of the remaining brine in the pore space, leading to substantial precipitation of salts and sulphate minerals, blocking the pores, and diminishing injectivity. On the other hand, carbonate dissolution of the acidified brine could cause the porosity to increase. Both can cause geomechanical effects taking into account the large pressure variations that can occur close to the injector. Especially in this area of modelling the need for coupled models, linking 
flow, chemistry and geomechanics (and temperature), is large. First attempts have started but a long way lies still ahead. Another challenge is the correct modelling of dissolution and precipitation reactions in extremely concentrated brines for which ion interaction models have to be applied (eg Pitzer approach) that are currently under development (as part of pure geochemical codes), but are rarely integrated in coupled codes at the moment.

Well integrity modelling goes to the heart of the risk assessment of $\mathrm{a}_{2}$ storage project since wells (both newly drilled ones as well as abandoned wells) are identified as a main concern with respect to leakage. Currently coupled flow and geochemical modelling in this area is essentially performed to elucidate cement interactions with $\mathrm{CO}_{2}$ on the laboratory scale. Modelled results confirm the occurrence of the experimentally and on-field observed carbonation reaction that can potentially reduce porosity. Since the mineralogy of cements is fundamentally different from that of geological materials, appropriate thermo-kinetic data at relevant P-T conditions are needed. This currently presents a serious limitation to the model outcomes. Upscaling of the results and taking into account the well geometry and potential mechanical effects of carbonation remain challenges in this application domain.

Finally, modelling of laboratory and small field scale experiments could aid the calibration of coupled geochemical models - although only for short term phenomena, taking into account the limited duration of experiments - before applying the models to longer timescales. However experiments are generally designed to observe processes rather than to perform a calibration. Furthermore experiments are generally set up at conditions and using materials as close as possible to the geological reality (using heterogeneous rocks or complex brine compositions for example) to reproduce geochemical reactions and their impacts as they occur in the field. Although this type of experiments allows to verify if geochemical reactions predicted by the models occur in reality, they do not allow for a calibration of the model in strict sense since too many parameters are involved and a unique interpretation is generally not possible. Specific experiments aimed at the calibration of one single reaction (eg pure albite dissolution generating dawsonite precipitation), at conditions relevant for $\mathrm{CO}_{2}$ storage, seem necessary. These experiments, specifically designed to apply and test the models, would allow for a more rigorous model calibration.

All four of the application domains are essential when it comes to assessing the impact of $\mathrm{CO}_{2}$ storage and prove that geochemistry is an intrinsic part of it that cannot be neglected. One of 
the main challenges when applying coupled modelling is that for the relevant temperature and pressure conditions and brine compositions, calculations have to be made outside the validity ranges of certain concepts that are generally integrated in geochemical models (eg ion association models, solubility calculations) and that are based on parameters values that were determined for different conditions. On top of that, it is generally difficult and expensive to acquire detailed geochemical parameters at high pressures and temperatures. As a consequence, insufficient accurate input data exist that are directly suitable for longer term geochemical modelling of $\mathrm{CO}_{2}$ storage applications. This induces large uncertainties in the model outcomes, especially when compared to uncertainty ranges generally encountered in pure physical (reservoir) modelling. Experimental work in specific $\mathrm{CO}_{2}$ storage contexts is needed to create reliable input parameters for coupled modelling. This lack of basic thermodynamical and kinetic data (especially for precipitating minerals) is a recurring issue in each of the four application domains.

New areas for geochemical and solute transport modelling in the $\mathrm{CO}_{2}$ storage domain are emerging. The need to investigate the link between flow, geochemistry and geomechanics is illustrated at several occasions. The possibility of co-injecting other gaseous compounds present in the gas stream as a result of capture process - together with $\mathrm{CO}_{2}$ is currently considered for economical reasons. The chemical reactivity of each of these compounds (eg $\mathrm{O}_{2}, \mathrm{~N}_{2}, \mathrm{NO}, \mathrm{SO}_{2}$ ) has to be evaluated and their mutual impact modelled, especially since some of them are far more reactive than $\mathrm{CO}_{2}$. This will require an important research effort with respect to the development of adequate equations of state (EOS) and solubility models, an effort that has only just started. Pore scale modelling applied to $\mathrm{CO}_{2}$ storage, describing the geochemical behaviour at the pore scale and clarifying the link between dissolutionprecipitation processes and porosity-permeability relations, is another area that is just emerging.

\section{Acknowledgements}

This work was funded by BRGM as part of the CO2SEQ framework research programme. 
References

André, L., Audigane, P., Azaroual, M., Menjoz, A., 2007, Numerical modelling of fluid-rock chemical interactions at the supercritical CO2-liquid interface during supercritical $\mathrm{CO} 2$ injection into a carbonate reservoir, the Dogger aquifer (Paris Basin, France). Energy Conversion and Management 48, 1782-1797.

Audigane, P., Gaus, I., Czernichowski-Lauriol, I., Pruess, K., Xu, T., 2006. A long term 2D vertical modelling of the $\mathrm{CO}_{2}$ storage at Sleipner (North Sea) using TOGHREACT. Proceedings in TOUGH Symposium, San Francisco, USA, 12-22 May 2006.

Audigane, P., Gaus, I., Czernichowski-Lauriol I., Pruess K., Xu, T, 2007(a).Two dimensional reactive transport modelling of $\mathrm{CO} 2$ injection in a saline aquifer at the Sleipner site, North Sea. American Journal of Science. In press.

Audigane, P., Oldenburg, C., van der Meer, B., Geel, C., Lions, J., Gaus, I., Robelin, Ch., Durst, P., Xu, T., 2007(b). Geochemical Modelling of the $\mathrm{CO}_{2}$ injection into a methane gas reservoir at the K12-B Field, North Sea. AAPG special publication on $\mathrm{CO}_{2}$ sequestration in geological media. In press.

Azaroual, M., Durst, P., Czernichowski-Lauriol, I., Olsen, D., Springer, N., Rochelle, C.A., Pearce, J., Bateman, K. \& Birchall, D., 2004. Geochemical reactions resulting from $\mathrm{CO} 2$ injection into the Midale formation, Weyburn oilfield; A laboratory experimental and modelling study. GHGT-7 - IEA Greenhouse Gas Technology Conference 2004. 59 September, 2004. Vancouver, Canada. IEA Greenhouse Gas Programme \& University of Regina. GHGT-7 Abstract volume, 5 p.

Azaroual, M., Pruess, K., Fouillac, C., 2007. Feasibility of using supercritical $\mathrm{CO}_{2}$ as heat transmission fluid in the EGS (Enhanced Geothermal Systems) integrating the carbon storage constraints. ENGINE - Enhanced Geothermal Innovative Network for Europe. Workshop 2: Exploring high temperature reservoirs: new challenges for geothermal energy. SIAF Campus, 1 - 4 April 2007, Volterra, Italy.

Baker, J.C., Bai, G.P., Hamilton, P.J., Golding, S.D., Keene, J.B., 1995. Continental-scale magmatic carbon dioxide seepage recorded by dawsonsite in the Bowen-GunnedahSydney Basin System, eastern Australia. Journal of Sedimentary Petrology, A65:22530. 
Bateman, K., Turner, G., Pearce, J.M., Noy, D.J., Birchall, D. and Rochelle, C.A., 2005.

Large-scale column experiment: study of $\mathrm{CO}_{2}$, porewater, rock reactions and model test case. Oil \& Gas Science and Technology - Rev. IFP 60 (1), 161-175.

Bénézeth, P., Palmer, D. A., Anovitz, L. M., Horita, J., 2007. Dawsonite synthesis and reevaluation of its thermodynamic properties from solubility measurements: implications for mineral trapping of $\mathrm{CO}_{2}$. Geochimica et Cosmochimica Acta, (In Press).

Bouc, O., Quisel, N., Le Gouevec, J., 2007. Risk and safety evaluation for $\mathrm{CO}_{2}$ geological storage. GEOTECHNOLOGIEN Science Report No. 9. 1st French-German Symposium on Geological Storage of CO2, June 21-22, 2007, Geoforschungszentrum Potsdam.

Burnol, A., Blanc, P. Xu, T., Spycher, N., Gaucher, E. C., 2006. Uncertainty in the reactive transport model response to an alkaline perturbation in a clay formation. In: Proceedings of the TOUGH Symposium 2006, May 2006, Berkeley, CA.

Cailly, B., Le Thiez, P., Egermann, P, Audibert, A., Vidal-Gilbert, S., Longaygue, X. (2005). Geological storage of $\mathrm{CO}_{2}$ : a state of the art of injection processes and technologies. Oil and Gas Science and Technology, 60, 517-525.

Carey, J.W., Duan, R..G., Kaszuba, J. P., 2006. Crystal chemistry and reactivity of dawsonite: GHGT-8, 8th International Conference on Greenhouse Gas Control Technologies, Trondheim, Norway, June 19-22.

Carey, J.W., Lichtner, P.C., 2007. Calcium silicate hydrate (C-S-H) solid solution model applied to cement degradation using the continuum reactive transport model FLOTRAN, in : Mobasher, B. and Skalny, J. (Eds.), Transport Properties and Concrete Quality: Materials Science of Concrete, Special Volume. American Ceramic Society; John Wiley \& Sons, Inc., pp. 73-106.

Carey, J.W., Wigand M., Chipera, S. J., Wolde G.G., Pawar, R., Lichtner, P.C., Wehner, S.C., Raines, M.A., Guthrie, G.D., 2007. Analysis and performance of oil well cement with 30 years of $\mathrm{CO}_{2}$ exposure from the SACROC Unit, West Texas, USA, International Journal of Greenhouse Gas Control 1, 75-85.

Carroll, S.A., Knauss, K.G., 2005. Dependence of labradorite dissolution kinetics on $\mathrm{CO}_{2}(\mathrm{aq})$, $\mathrm{Al}(\mathrm{aq})$, and temperature, Chem. Geol. 217, 213-225.

Chadwick, A, Noy, D, Lindeberg, E., Arts, R., Eiken, O., Williams, G. (2006). Calibrating reservoir performance with time-lapse seismic monitoring and flow simulations of the Sleipner CO2 plume. Proceedings of the GHGT8 conference - Trondheim (Norway), $18-22 / 06 / 2006$. 
Chou, L., Garrels, R.M., Wollast, R., 1989. Comparative study of the kinetics and mechanisms of dissolution of carbonate minerals. Chem. Geol. 78, 269-282.

Chou, L., Wollast, R., 1985. Steady-state kinetics and dissolution mechanisms of albite. Am. J. of Sci. 285, 963-993.

Czernichowski-Lauriol, I., Rochelle, C., Lindeberg, E., Bateman, L., and Sanjuan, B. (1996). Analysis of the geochemical aspects of the underground disposal of $\mathrm{CO}_{2}$. In Deep Injection Disposal of Hazardous and Industrial Waste: Scientific and Engineering Aspects (ed. J. A. Apps and C. F. Tsang), pp. 565-585. Academic Press.

De Windt, L. , Pellegrini, D., van der Lee, J., 2004. Coupled modelling of cement/claystone interactions and radionuclide migration. Journal of Contaminant Hydrology 68, 165182.

Duan, Z., Moller, N., Weare, J.H., 1992. An equation of state for the $\mathrm{CH}_{4}-\mathrm{CO}_{2}-\mathrm{H}_{2} \mathrm{O}$ system: 1. Pure systems from $0^{\circ}$ to $1000^{\circ} \mathrm{C}$ and 0 to 8000 bar. Geochimica et Cosmochimica Acta 56, 2605-2617.

Duan, Z., Sun, R., 2003. An improved model for calculating $\mathrm{CO}_{2}$ solubility in pure water and aqueous $\mathrm{NaCl}$ solutions from 273 to $533 \mathrm{~K}$ and from 0 to 2000bar. Chem. Geol. 193, 253-27.

Emberley, S., Hutcheon, I.,Shevalier, M., Durocher, K., Mayer, B., Gunter W., Perkins, E., (2005). Monitoring of fluid-rock interaction and CO2 storage through produced fluid sampling at the Weyburn CO2-injection enhanced oil recovery site, Saskatchewan, Canada, Applied Geochemistry 20, 1131-1157.

Ennis-King, J., Paterson L., 2003. Role of convective mixing in the long-term storage of carbon dioxide in deep saline formations: Paper SPE-84344, presented at the Society of Petroleum Engineers Annual Fall Technical Conference and Exhibition, Denver, CO, October 2003, Paper SPE-84344.

Fischer, M., Botz, R., Schmidt, M., Rockenbauch., K., Garbe-Schönberg, D., Glodny, J., Gerling, P., Littke, R., 2006. Origins of $\mathrm{CO} 2$ in permian carbonate reservoir rocks (Zechstein, Ca2) of the NW-German Basin (Lower Saxony). Chemical Geology 227, 184-213.

Frangeul, J., Nghiem, L., Emmanuel, C., Thibeau, S., 2004, Sleipner/Utsira $\mathrm{CO}_{2}$ geological storage: full field flow and geochemical coupling to assess the long term fate of the $\mathrm{CO}_{2}$ : Proceedings AAPG Annual Conference, Dallas, Texas, 18-21 April, 2004, Paper AAPG 86278. 
Gaus, I., Le Guern, C., Pearce, J., Pauwels, H., Shepherd, T., Hatziyannis, G., Metaxas, A., 2004, Comparison of long term geochemical interactions at two natural $\mathrm{CO}_{2}$ analogues: Montmiral (Southeast basin, France) and Messokampos (Florina basin, Greece) case studies, in Rubin, E.S., Keith, D.W. and Gilboy, C.F., Editors, Proceedings of the $7^{\text {th }}$ International Conference on Greenhouse Gas Control Technologies, Volume 1, Peer-Reviewed Papers and Plenary Presentations: Cheltenham, UK, IEA Greenhouse Gas Program.

Gaus, I., Azaroual, M., Czernichowski-Lauriol, I., 2005, Reactive transport modelling of the impact of $\mathrm{CO}_{2}$ injection on the clayey cap rock at Sleipner (North Sea). Chemical Geology 217, 319-337.

Glassley, W.E., Simmons, A.M., Kercher J.R., 2002. Mineralogical heterogeneity in fractured, porous media and its representation in reactive transport models. Applied Geochemistry 17, 699-708.

Golfier, F, Bazin, B, Zarcone, C, Lernormand, R, Lasseux, D, Quintard, M., 2001. Acidizing carbonate reservoirs: numerical modelling of wormhole propagation and comparision to experiments. SPE 68922, SPE European Formation Damage Conference, The Hague, Netherlands, 21-22 May 2001.

Gunter, W.D., Perkins, E.H., Hutcheon, I., 2000. Aquifer disposal of acid gases: modelling of water-rock reactions for trapping of acid wastes. Applied Geochemistry, 15, p. 1085 1095.

Gunter, W.D., Wiwchar, B., Perkins, E. H., 1997. Aquifer disposal of $\mathrm{CO}_{2}$-rich greenhouse gases: extension of the time scale of experiment for $\mathrm{CO} 2$-sequestering reactions by geochemical modelling. Mineralogy and Petrology 59, 121-140.

Haszeldine, R.S., Quinn, O., England, G., Wilkinson, M., Shipton, Z.K., Evans, J.P., Heath, J., Crossey, L., Ballentine, C.J., Graham, C.M., 2005. Natural geochemical analogues for carbon dioxide storage and sequestration in deep geological porous reservoirs. Oil and Gas Science and Technology 60, 33-49.

Hellevang, H., Aagaard, P., Oelkers, E., Kvamme, B., 2005. Can dawsonite permanently trap $\mathrm{CO}_{2}$ ? Environ. Sci. Technol. 39, 8281-8287.

Hesjevik, S.M., Solsen, S., Seiersten, M., 2003. Corrosion at high $\mathrm{CO}_{2}$ pressure. Corrosion 2003 paper 03345, San Diego 16-20 March 2003.

Hitchon, B., 1996. Aquifer disposal of carbon dioxide. In Hitchon, B, (ed). Sherwood Park, Alberta, Canada, Geoscience Publishing Limited. 
Holloway, S., 1997. An overview of the underground disposal of carbon dioxide. Energy Conversion and Management 38, 193-198.

Huertas, F.J., Chou, L., Wollast, R., 1999. Mechanism of kaolinite dissolution at room temperature and pressure. Geochim. Cosmochim. Acta 63, 3261-3275.

IPCC (2006). Special Report on Carbon dioxide Capture and Storage. http://www.ipcc.ch/activity/srccs/

Itasca Consulting Group Inc., 1997, FLAC-3D manual: Fast Lagrangian Analysis of Continua in 3 Dimensions - Version 2.0. Itasca Consulting Group Inc., Minnesota, USA.

Jacquemet, N., 2006. Durabilité des matériaux de puits pétroliers dans le cadre d'une sequestration géologique de dioxide de carbone et d'hydrogène sulfuré/Well materials durability in case of carbon dioxide and hydrogen sulphide geological sequestration. $\mathrm{PhD}$, Université Henri Poincaré, Nancy, France. Available at http://tel.archivesouvertes.fr/tel-00084391/en/.

Jacquemet, N., Pironon, J., Caroli, E., 2005, A new experimental procedure for simulation of $\mathrm{H}_{2} \mathrm{~S}+\mathrm{CO}_{2}$ geological storage. Oil and Gas Science and Technology - Rev. IFP 60, 193-206.

Jacquemet, N., Pironon, J., Saint-Marc, J., 2007. Mineralogical changes of a well cement in various $\mathrm{H}_{2} \mathrm{~S}-\mathrm{CO}_{2}$ (-brine) fluids at high pressure and temperature. Accepted for Environmental Science and Technology.

Johnson, J.W., Oelkers, E.H., Helgeson, H.C., 1992. SUPCRT92: A software package for calculating the standard molal thermodynamic properties of minerals, gases, aqueous species, and reactions from 1 to 5000 bars and 0 to $1000^{\circ} \mathrm{C}$ : Computers and Geosciences 18, 7. 899-947.

Johnson, J.W., Lundeen, S.R., 1994. GEMBOCHS thermodynamic data files for use with the EQ3/6 software package: Lawrence Livermore National Laboratory, Livermore, California, LLNL-YMP Milestone report MOL72, 99 p.

Johnson, J.W., Nitao, J.J., Steefel, C., Knaus, K.G., 2001, Reactive transport modelling of geological $\mathrm{CO}_{2}$ sequestration in saline aquifers; The influence of intra-aquifer shales and the relative effectiveness of structural, solubility, and mineral trapping during prograde and retrograde sequestration: First annual conference on carbon sequestration, may $14-17^{\text {th }}$, Washington, 2001. 
Juanes, R., Spiteri, E.J., Orr Jr., F.M., Blunt M.J., 2006. Impact of relative permeability hysteresis ongeological $\mathrm{CO}_{2}$ storage. Water Res. Res. 42, W12418, doi:10.1029/2005WR004806.

Kaszuba, J.P., Janecky, D.R., Snow, M.G., 2003. Carbon dioxide reaction processes in a model brine aquifer at $200{ }^{\circ} \mathrm{C}$ and 200 bars: implications for geologic sequestration of carbon, Applied Geochemistry 18, 1065-1080.

Kaszuba J.P., Janecky D.R., Snow, M.G., 2005. Experimental evaluation of mixed fluid reactions between supercritical carbon dioxide and $\mathrm{NaCl}$ brine: relevance to the integrity of a geologic carbon repository. Chemical Geology 217, 277-293.

Kervévan, C., Azaroual, M., Durst, P., 2005. Improvement of the calculation accuracy of acid gas solubility in deep reservoir brines : application to the geological storage of $\mathrm{CO}_{2}$. Oil \& Gas Science and Technology 60, 357-379.

Kharaka, Y.K., Cole, D.R., Hovorka, S.D., Gunter, W.D., Knauss, K.G., Freifeld, B.M., 2006. Gas-water-rock interactions in Frio Formation following CO2 injection: Implications for the storage of greenhouse gases in sedimentary basins. Geology 34, 577-580.

Kharaka, Y.K., Gunter, W.D., Aggarwal, P.K., Perkins, E.H., De Braal, J.D., 1988. SOLMINEQ.88: a computer program code for geochemical modelling of water-rock interactions. In: US Geol. Surv. Water Res. Investigations Rept, 88-4227.

Knauss, K., Johnson, J.W. and Steefel, C.I., 2005. Evaluation of the impact of $\mathrm{CO}_{2}$, cocontaminant gas, aqueous fluid and reservoir-rock interactions on the geologic sequestration of CO2, Chem. Geol. 217, 339-350.

Kovler, K., Zhutovsky, S., 2006. Overview and future trends of shrinkage research. Materials and Structures 39, 827-847.

Le Gallo, Y., Trenty, L., Michel, A., Vidal-Gilbert, S., Parra, T., Jeannin, L., 2006. Long-term flow simulations of $\mathrm{CO}_{2}$ storage in saline aquifer. Proceedings of the GHGT8 conference - Trondheim (Norway), 18-22/06/2006.

Lagneau, V, Pipart, A, Catalette, H., 2005. Reactive transport modelling of $\mathrm{CO}_{2}$ sequestration in deep saline aquifers. Oil and Gas Science and Technology-Rev IFP 60(2), 231-247.

Lasaga, A.C., 1984. Chemical kinetics of water-rock interactions. J. Geophys. Res. 89, 40094025 .

Lindeberg, E., Bergmo, P., 2002, The long term fate of $\mathrm{CO}_{2}$ injected into an aquifer: Proceedings of the $6^{\text {th }}$ International Conference on Greenhouse Gas Control Technology: Kyoto, Japan, 1-4 October 2002 
Lindeberg, E., Zweigel, P., Bergmo, P., Ghaderi, A., Lothe, A., 2000, Prediction of $\mathrm{CO}_{2}$ dispersal pattern improved by geology and reservoir simulation and verified by time lapse seismic: Proceedings of the $5^{\text {th }}$ International Conference on Greenhouse Gas Control Technologies, Cairns (Australia), August 2000.

Maltais, Y., Samson, E., Marchand, J., 2004. Predicting the durability of Portland cement systems in aggressive environments - Laboratory validation. Cement and Concrete Research 34, 1579-1589.

May, F., 2005. Alteration of wall Rocks by $\mathrm{CO}_{2}$-rich water ascending in fault zones: natural analogues for reactions Induced by $\mathrm{CO}_{2}$ migrating along faults in siliciclastic reservoir and cap rocks. Oil and Gas Science and Technology 60, 19 - 32.

Metz, V., Ganor, J., 2001. Stirring effect on kaolinite dissolution rate. Geochim. Cosmochim. Acta $65,3475-3490$.

Moore, J., Adams, M., Allis, R., Lutz, S., Rauzi, S., 2005. Mineralogical and geochemical consequences of the long term presence of $\mathrm{CO} 2$ in natural reservoirs: An example from the Springerville-St. Johns field, Arizona and New Mexico, U.S.A. Chemical Geology 217, 183-186.

Nghiem, L., Sammon, P., Grabenstetter, J., Ohkuma, H., 2004. Modelling $\mathrm{CO}_{2}$ storage in aquifers with a fully-coupled geochemical EOS compositional simulator: Proceedings SPE 89474 for the SPE/DOE $14^{\text {th }}$ Symposium on Improved Oil recovery, Tulsa, Oklahoma, 17-21 April, 2004, Paper SPE-89474.

Nitao, J.J., 1998. Reference manual for the NUFT flow and transport code, version 2.0: Lawrence Livermore National Laboratory, Livermore, California, UCRL-MA-130651, $55 \mathrm{p}$.

Obi, E-O. I., Blunt, M. J., 2006. Streamline-based simulation of carbon dioxide storage in a North Sea aquifer, Water Resources Research 42, W03414, doi:10.1029/2004WR003347.

Oldenburg, C., Benson, S., 2002. $\mathrm{CO}_{2}$ injection for enhanced gas production and carbon sequestration: Proceedings SPE 74367 presented at the SPE International Petroleum Conference and Exhibition, Mexico, 10-12 February 2002, Paper SPE 74367.

Ozah, R.C., Lakshminarasimhan, S., Pope, G.A., Sepehrnoori, K., Bryant, S.L., 2005. Numerical simulation of the storage of pure $\mathrm{CO} 2$ and $\mathrm{CO} 2-\mathrm{H} 2 \mathrm{~S}$ gas mixtures in deep saline aquifers, proceedings SPE 97255, Technical conference and exhibition, Dallas, U.S.A., 9-12 October 2005. 
Palandri, J., Kharaka, Y.K., 2004. A compilation of rate parameters of water-mineral interaction kinetics for application to geochemical modelling. US Geological Survey Open File Report 2004-1068, 64pp.

Parkhurst, D.L., Appelo, C.A.J., 1999. User's guide to PHREEQC (version 2)--A computer program for speciation, batch-reaction, one-dimensional transport, and inverse geochemical calculations: U.S. Geological Survey Water-Resources Investigations, Report 99-4259, 312 p.

Pearce, J.M., Gaus, I., Pauwels, H., Le Nindre, Y.-M., Girard, J.-P., Shepherd, T.J., (in prep). Long term geochemical interactions at Montmiral (France), an analogue for a geological $\mathrm{CO} 2$ storage site. In preparation for Applied Geochemistry.

Perkins, E.H., Gunter, W.D., 1995. Aquifer disposal of CO2-rich greenhouse gasses: modelling of water-rock reaction paths in a siliciclastic aquifer. In Water-rock Interactions (Y.K. Kharaka and O.V. Chudaev (editors)), pp895-898 Rotterdam, Brookfield.

Pfingsten, W., 2002. Experimental and modelling indications for self-sealing of a cimentitious low- and intermediate-level waste repository by calcite precipitation. Nuclear Technology 140, 63-82.

Pitzer, K.S., 1991. Ion interaction approach: Theory and data correlation. In Activity Coefficients in Electrolytes Solutions, edited by K. S. Pitzer, 2nd ed., CRC Press, p. 75155.

Pitzer, K.S., 1973. Thermodynamics of electrolytes, 1, Theoretical basis and general equations, J.Phys.Chem. 77, 268-277.

Plummer, L.N., Parkhurst, D.L., Wigley, T.M.L., 1978. The kinetics of calcite dissolution in CO2-water systems at 5-60 C and 0.0-1.0 atm $\mathrm{CO}_{2}$. Am. J. Sci. 278, 176-216.

Pokrovsky, O.S., Golubev, S.V., Schott, J., 2005. Dissolution kinetics of calcite, dolomite and magnesite at $25^{\circ} \mathrm{C}$ and 0 to $50 \mathrm{~atm} \mathrm{pCO}_{2}$. Chem. Geol. 217, 239-255.

Pomès V., Bazin B., Golfier F., Zarcone C., Lenormand R.., Quintard M., 2001. “On The Use of Upscaling Methods to Describe Acid Injection in Carbonates”. SPE 71511

Pruess, K., 1987. Tough user's guide: Nuclear Regulatory Commission , report NUREG/CR4645 (also Lawrence Berkeley Laboratory Report LBL-20700, Berkeley, California).

Pruess, K., 1991. TOUGH2 - a general-purpose numerical simulator for multiphase fluid and heat flow: Lawrence Berkeley Laboratory Report LBL-29400, Berkeley, California. 
Pruess, K., 2004, The TOUGH codes- A family of simulation tools for multiphase flow and transport processes in permeable media: Vadose Zone Journal, Special section, Research advances in vadoze zone hydrology through simulations with the TOUGH codes, v. 3, p. 738-746.

Pruess, K., García, J., Kovscek, T., Oldenburg, C., Rutqvist, J. Steefel, C., Xu, T., 2002. Intercomparison of numerical simulation codes for geologic disposal of $\mathrm{CO}_{2}$, Lawrence Berkeley Laboratory Report LBNL-51813, Berkeley, California.

Pruess, K., García, J., Kovscek, T., Oldenburg, C., Rutqvist, J. Steefel, C., Xu, T., 2004. Code intercomparison builds confidence in numerical simulation models for geologic disposal of $\mathrm{CO}_{2}$ : Energy 29, 1431-1444.

Pruess, K., Xu, T., Apps, J., García, J., 2001. Numerical Modelling of Aquifer Disposal of $\mathrm{CO}_{2}$ : Proceedings SPE66537 presented at the SPE/EPA/DOE Exploration and Production Environmental Conference, San Antonio, Texas, 26-28 February, 2001, Paper SPE66537.

Pruess; K., García, J., 2002. Multiphase flow dynamics during $\mathrm{CO}_{2}$ disposal into saline aquifers, Environmental Geology. 42, 282-295.

Regnault O., Lagneau V., Catalette H., Schneider H., 2005, Etude expérimentale de la réactivité du $\mathrm{CO} 2$ supercritique vis-à-vis de phases minérales pures. Implications pour la séquestration géologique de CO2, C. R. Géoscience 337, 1331-1339.

Regnault, O., Lagneau, V., Catalette, H., Schneider, H., 2005. Etude expérimentale de la réactivité du $\mathrm{CO} 2$ supercritique vis-à-vis de phases minérales pures. Implications pour la séquestration géologique de CO2. Comptes Rendus Geosciences 337, 1331-1339.

Rochelle, C.A., Czernichowski-Lauriol, I., Milodowski, A.E., 2004. The impact of chemical reactions in $\mathrm{CO}_{2}$ storage in geologic formations: a brief review. In Baines, S.J. and Worden, R.H. (eds). Geological Storage of Carbon Dioxide. Geological Society, London, Special Publications, 233 87-106.

Rosenbauer, R.J., Koksalan, T., Palandri, J.L., 2005. Experimental investigation of $\mathrm{CO}_{2}$ brine-rock interactions at elevated temperature and pressure: implications for $\mathrm{CO}_{2}$ sequestration in deep-saline aquifers. Fuel Proc Technol, 86, 1581-1597.

Rudqvist, J., Birkholzer, J., Tsang, C.-F., 2006. Modelling hydrological and geochemical processes related to $\mathrm{CO} 2$ injection in a faulted multilayer system. Proceedings of the GHGT8 conference - Trondheim (Norway), 18-22/06/2006. 
Shiraki R., Dunn T.L., 2000. Experimental study on water-rock interactions during CO2

flooding in the Tensleep Formation, Wyoming, USA. Applied Geochemistry 15(3), 265279.

Shock, E.L., 1998. An updated and augmented version (slop98.dat) of the original SUPCRT92 database (sprons92.dat). http:/zonvark.wustl.edu/geopig.

Steefel, C.I., Depaolo, D.J., Lichtner, P.C., 2005. Reactive transport modelling: an essential tool and a new research approach for the earth sciences. Earth and Planetary Science Letters 240, 539-558.

Taylor, H. W. F., 1997. Cement chemistry, second ed. Thomas Telford, London..

Thibeau, S., Nghiem, L.X., 2007. A modelling study of the role of selected minerals in enhancing $\mathrm{CO}_{2}$ mineralisation during $\mathrm{CO}_{2}$ aquifer storage. SPE109739.

Thiery, M., 2005. Modélisation de la carbonatation atmosphérique des matériaux cimentaires. Prise en compte des effets cinétiques et des modifications microstructurales et hydroliques. Thèse, Ecole Nationale des Ponts et Chaussées, Paris, France. Available at: http://pastel.paristech.org/1517/02/these-thiery.pdf.

Torp, T.A., Gale, J., 2002. Demonstrating storage of CO2 in geological reservoirs: the Sleipner and SACS projects. Proceedings of the 6th International conference on Greenhouse Gas Control Technology (GHGT-6), Kyoto, Japan, 1-4 October 2002.

Trotignon, L., Peycelon, H., Bourbon, X., 2006. Comparison of performance of concrete barriers in a clayey geological medium, Physics and Chemistry of the Earth, Parts $\mathrm{A} / \mathrm{B} / \mathrm{C}, 31,610-617$.

Van der Meer, B., Kreft, E., Geel, C., Hartman, J., 2004. K12-B site a test site forCO2 storage and enhanced gas recovery, proceeding SPE/IADC 94128, 14th Europec Biennal Conference held in Madrid, Spain, 13-16 June 2005.

Watson, M.N., Zwingmann, N., Lemon, N.M., 2004. The Ladbroke Grove-Katnook carbon dioxide natural laboratory: a recent $\mathrm{CO}_{2}$ accumulation in a lithic sandstone reservoir, Energy 29, 1457 - 1466.

Weir, G., White, S.P., Kissling, W., 1996. Reservoir storage and containment of greenhouse gases, Transport in porous media. 23, 37-60.

White, A.F., Peterson, M.L., 1990. Role of reactive surface area characterization in geochemical models. Chemical modelling of aqueous systems II. In: Melchior, D.C., Bassett, R.L. (Eds.). Am. Chem. Soc. Symp. Ser. 416, 416-475. 
White, S.P., Weir, G., Kissling, W., 2001. Numerical simulation of $\mathrm{CO}_{2}$ sequestration in natural $\mathrm{CO}_{2}$ reservoirs on the Colorado Plateau: Proceedings of the $1^{\text {st }}$ National Conference on Carbon Sequestration, Washington D.C., May 2001.

White, S.P., Allis, R.G., Moore, J., Chidsey, T., Morgan, C., Gwynn, W., Adams, M., 2005. Simulation of reactive transport of injected $\mathrm{CO}_{2}$ on the Colorado Plateau, Utah, USA. Chem. Geol. 217, 387-405.

Wilson, M., Monea, M., 2004. IEA GHG Weyburn CO2 monitoring \& storage project Summary Report 2000-2004. Petroleum Technology Research Centre, Canada.

Worden, R.H., (2006). Dawsonite cement in the Triassic Lam Formation, Shabwa Basin, Yemen: A natural analogue for a potential mineral product of subsurface $\mathrm{CO}_{2}$ storage for greenhouse gas reduction.. Marine and Petroleum Geology 23, 61-77.

Xu, T., Apps, J., Pruess, K., 2003. Reactive geochemical transport simulation to study mineral trapping for $\mathrm{CO}_{2}$ disposal in deep arenaceous formations: Journal of Geophysical Research, v. 108, (B2), p. 2071, doi:10.1029/2002JB001979.

$\mathrm{Xu}, \mathrm{T} .$, Apps, J., Pruess, K., 2004. Numerical simulation of $\mathrm{CO}_{2}$ disposal by mineral trapping in deep aquifers. Applied geochemistry 19, 917-936.

Xu, T., Apps, J., Pruess, K., 2005, Mineral sequestration of a sandstone-shale system. Chemical geology 217, 295-318.

$\mathrm{Xu}, \mathrm{T}$., Pruess, K., 2001. Modelling multiphase non-isothermal fluid flow and reactive geochemical transport in variably saturated fractured rocks: 1. Methodology: American Journal of Science 301, 16-33.

Xu, T., Sonnenthal E., Spycher N., Pruess, K., 2006. TOUGHREACT - A simulation program for non-isothermal multiphase reactive geochemical transport in variably saturated geologic media: applications for geothermal injectivity and $\mathrm{CO} 2$ geologic sequestration. Computers and Geosciences 32, 145-165.

Xu, T., Apps, J.A., Pruess, K., Yamamotob, H., 2007. Numerical modeling of injection and mineral trapping of $\mathrm{CO}_{2}$ with $\mathrm{H}_{2} \mathrm{~S}$ and $\mathrm{SO}_{2}$ in a sandstone formation. Chemical Geology 242, 319-346.

Yeh, G.T., Tripathi, V.S., 1991, A model for simulating transport of reactive multi-species components: Model development and demonstration: Water Resource Research 27, 3075-3094.

Yokozeki, K., Watanabe, K., Sakata, N., Otsuki, N., 2004. Modelling of leaching from cementitious materials used in underground environment. Applied Clay Science 26, 293-308. 
Zerai B., Saylor B.Z., Matisoff G., 2006. Computer simulation of $\mathrm{CO}_{2}$ trapped through mineral precipitation in the Rose Run Sandstone, Ohio. Appl. Geochem. 21, 223-240.

Zhang, G., Zheng, Z., Wan, J. (2005). Modeling reactive geochemical transport of concentrated aqueous solutions. Water Resources Research41, W02018, doi:10.1029/2004WR003097.

Zhang, G., Spycher, N., Sonnenthal, E., Steefel, C., 2006. Implementation of a Pitzer activity model into TOUGHREACT for modelling concentrated solutions. Proceedings, TOUGH Symposium 2006, Lawrence Berkeley National Laboratory, Berkeley, California, May 15-17 (Report LBNL-60016).

Zhou, W., Stenhouse, M., Arthur, R., Whittaker, S., Law, D., Chalaturnyk, R., Jazrawi, W., 2004, The IEA Weyburn $\mathrm{CO}_{2}$ monitoring project modelling of the long term migration of $\mathrm{CO}_{2}$ from Weyburn, in Rubin, E.S., Keith, D.W. and Gilboy, C.F., editors, Proceedings of the $7^{\text {th }}$ International Conference on Greenhouse Gas Control Technologies, Volume 1, Peer-Reviewed Papers and Plenary Presentations: Cheltenham, UK, IEA Greenhouse Gas Program.

Zhu, C., Burden, D.S., 2001. Mineralogical compositions of aquifer matrix as necessary initial conditions in reactive contaminant transport models. Journal of Contaminant Hydrology $51,145-161$. 
List of figures.

Figure 1 Application domains of geochemical and solute transport modelling relevant to $\mathrm{CO}_{2}$ storage and their time and space scales.

Figure 2. Storage security depends on a combination of physical and geochemical trapping. Over time, the physical process of residual $\mathrm{CO}_{2}$ trapping and geochemical processes of solubility trapping and mineral trapping increase (IPCC, 2006).

Figure 3. Main parameters influencing the injectivity index and their relations between them.

Figure 4. $\mathrm{CO}_{2}$ density as a function of temperature and pressure based on the equation of state (EOS) from Duan et al (1992).

Figure 5. Concentration of dissolved $\mathrm{CO}_{2}$ (in mol per $\mathrm{kg}$ water) as a function of temperature and pressure in pure water (left) and in a $200 \mathrm{~g} / 1$ brine (right) as derived from the Duan and Sun (2003) model.

Figure 6. Amount of calcite dissolved in $\mathrm{NaCl}$ solutions at $60^{\circ} \mathrm{C}$ under a $\mathrm{pCO}_{2}$ of 100 bar calculated with different formalisms (Pitzer, Davies, b-dot).

Figure 7. Comparison of modelled dissolution rates for dolomite, kaolinite and albite at $25^{\circ} \mathrm{C}$ based on Palandri and Kharaka (2004), Gunter et al. (2000), Xu et al. (2005), Chou et al. (1989), White et al. (2000).

Figure 8.. Conceptual diagram of the reactive zones around the injection well as derived fro coupled modelling (Azaroual et al., 2007). The different radii $\left(r_{1}, r_{2}, r_{3}, r_{4}\right)$ are dependent on $\mathrm{CO}_{2}$ injection flow rate and rock properties $\left(\mathrm{S}_{\mathrm{G}}\right.$ : gas saturation, $\mathrm{S}_{\mathrm{L}}$ : liquid saturation).

Figure 9. Conceptualisation of carbonation fronts of cement based on five modelling studies. 
List of tables

Table 1. Overview of published solute transport models that refer to the Utsira saline aquifer storage case at the Sleipner site, their main characteristics and findings.

Table 2. Characteristics of the cement/ $\mathrm{CO}_{2}$ interaction modelling studies. 
Table 1. Overview of published coupled models that refer to the Utsira saline aquifer storage case at the Sleipner site, their main characteristics and findings.

\begin{tabular}{|c|c|c|c|c|}
\hline Reference & Geometry & Geochemistry & $\begin{array}{l}\text { Simulation } \\
\text { time }\end{array}$ & Major conclusions \\
\hline $\begin{array}{l}\text { Gaus et al. } \\
(2004)\end{array}$ & $\begin{array}{l}\text { 1D aqueous modelling } \\
\text { assuming diffusion in } \\
\text { caprock only }\end{array}$ & $\begin{array}{l}\text { Complete mineralogy } \\
\text { using transition state } \\
\text { theory reaction kinetics }\end{array}$ & 3000 years & $\begin{array}{l}\text { Porosity change in caprock negligible, slight } \\
\text { decrease in porosity possible, except at the } \\
\text { reservoir/caprock interface }\end{array}$ \\
\hline $\begin{array}{l}\text { Johnsson et } \\
\text { al. (2001) }\end{array}$ & $\begin{array}{l}\text { 2D model including } \\
\text { reservoir, caprock, with } \\
\text { inter aquifer clay layers }\end{array}$ & $\begin{array}{l}\text { Complete mineralogy } \\
\text { using transition state } \\
\text { theory reaction kinetics }\end{array}$ & 20 years & $\begin{array}{l}\text { Intra-aquifer shales extend the volumetric extent } \\
\text { of plume-aquifer interaction, } 85 \% \text { remains as SC- } \\
\mathrm{CO} 2,15 \% \text { dissolves and } 1 \% \text { precipitates. } \\
\text { Important reduction in microfracture porosity in } \\
\text { the caprock. }\end{array}$ \\
\hline $\begin{array}{l}\text { Frangeul et } \\
\text { al. (2005) }\end{array}$ & $\begin{array}{l}3 \mathrm{D} \text { homogeneous } \\
\text { reservoir model }\end{array}$ & $\begin{array}{l}\text { Carbonate mineralogy } \\
\text { only. Not clear if } \\
\text { kinetics is included }\end{array}$ & 6000 years & $\begin{array}{l}\text { After } 6000 \text { years } 55 \% \text { of the } \mathrm{CO} 2 \text { in dissolved } \\
\text { form, } 42 \% \text { in ionic form, none precipitated }\end{array}$ \\
\hline $\begin{array}{l}\text { Thibeau } \\
\text { and Nghiem } \\
(2007)\end{array}$ & $\begin{array}{l}\text { 3D homogeneous } \\
\text { reservoir model, on a } \\
\text { coarse grid }\end{array}$ & $\begin{array}{l}\text { Complete mineralogy } \\
\text { using transition state } \\
\text { theory kinetics }\end{array}$ & 18000 years & $\begin{array}{l}\text { Depending on the initial mineralogy, between } \\
40 \% \text { and } 100 \% \text { of the } \mathrm{CO} 2 \text { is trapped in minerals } \\
\text { after } 10000 \text { years. }\end{array}$ \\
\hline $\begin{array}{l}\text { Audigane et } \\
\text { al. (2007) }\end{array}$ & $\begin{array}{l}\text { 2D radial reservoir } \\
\text { model with inter aquifer } \\
\text { clay layers }\end{array}$ & $\begin{array}{l}\text { Complete mineralogy } \\
\text { using transition state } \\
\text { theory kinetics }\end{array}$ & 10000 years & $\begin{array}{l}95 \% \text { of } \mathrm{CO} 2 \text { dissolved in the brine, } 5 \% \text { taken up } \\
\text { by minerals after } 10000 \text { years }\end{array}$ \\
\hline
\end{tabular}


Table 2. Characteristics of the cement $/ \mathrm{CO}_{2}$ interaction modelling studies.

\begin{tabular}{|c|c|c|c|c|c|c|c|}
\hline \multirow[t]{2}{*}{$\begin{array}{l}\text { Refere } \\
\text { nce }\end{array}$} & \multicolumn{2}{|c|}{ Initial carbon concentration } & \multicolumn{2}{|c|}{$\begin{array}{c}\text { Initial pH (at simulation } \\
\text { P-T) }\end{array}$} & \multirow[t]{2}{*}{$\begin{array}{c}\text { One- or two- } \\
\text { phase conditions }\end{array}$} & \multirow[t]{2}{*}{$\begin{array}{l}\text { Simulated P-T } \\
\text { conditions }\end{array}$} & \multirow[t]{2}{*}{$\begin{array}{c}\text { Cement } \\
\text { domain } \\
\text { length }\end{array}$} \\
\hline & $\begin{array}{l}\text { Cement } \\
\text { domain }\end{array}$ & $\begin{array}{l}\text { External } \\
\text { media }\end{array}$ & $\begin{array}{l}\text { Cement } \\
\text { domain }\end{array}$ & $\begin{array}{l}\text { External } \\
\text { media }\end{array}$ & & & \\
\hline $\mathrm{P}$ & $7.810^{-6} \mathrm{~mol} / 1$ & $1.610^{-2} \mathrm{~mol} / 1$ & 12.7 & 7.3 & One-phase (brine) & (room conditions?) & $<1 \mathrm{~m}$ \\
\hline $\mathrm{J}$ & $\mathrm{CO}_{2}$-free & $1.1 \mathrm{~mol} / 1$ & 8.5 & 4.8 & One-phase (brine) & 500 bar $-200^{\circ} \mathrm{C}$ & $0.0015 \mathrm{~m}$ \\
\hline B et al. & $9.010^{-6}$ molal & $\begin{array}{l}7.010^{-4} \\
\text { molal }\end{array}$ & 11.7 & 7.6 & $\begin{array}{c}\text { Two-phase } \\
\text { (brine+CO2 in } \\
\text { cement, brine only } \\
\text { in external media) }\end{array}$ & $\begin{array}{c}1 \text { bar- } 50^{\circ} \mathrm{C} \\
\text { (cement domain), } \\
50 \text { bar- }-25^{\circ} \mathrm{C} \\
\text { (external media) }\end{array}$ & $2 \mathrm{~m}$ \\
\hline $\begin{array}{l}\mathrm{C} \text { and } \mathrm{L} \\
\text { and } \mathrm{C} \\
\text { et al. }\end{array}$ & $\mathrm{CO}_{2}$-free & $\mathrm{p}_{\mathrm{CO} 2}=180 \mathrm{bar}$ & 13 & 5 & One-phase (brine) & 180 bar $-25^{\circ} \mathrm{C}$ & $0.25 \mathrm{~m}$ \\
\hline
\end{tabular}

P: Pfingsten (2002); J: Jacquemet (2006); B et al.: Burnol et al. (2006); C and L: Carey and Lichtner (2007); C and al.: Carey et al. (2007) 


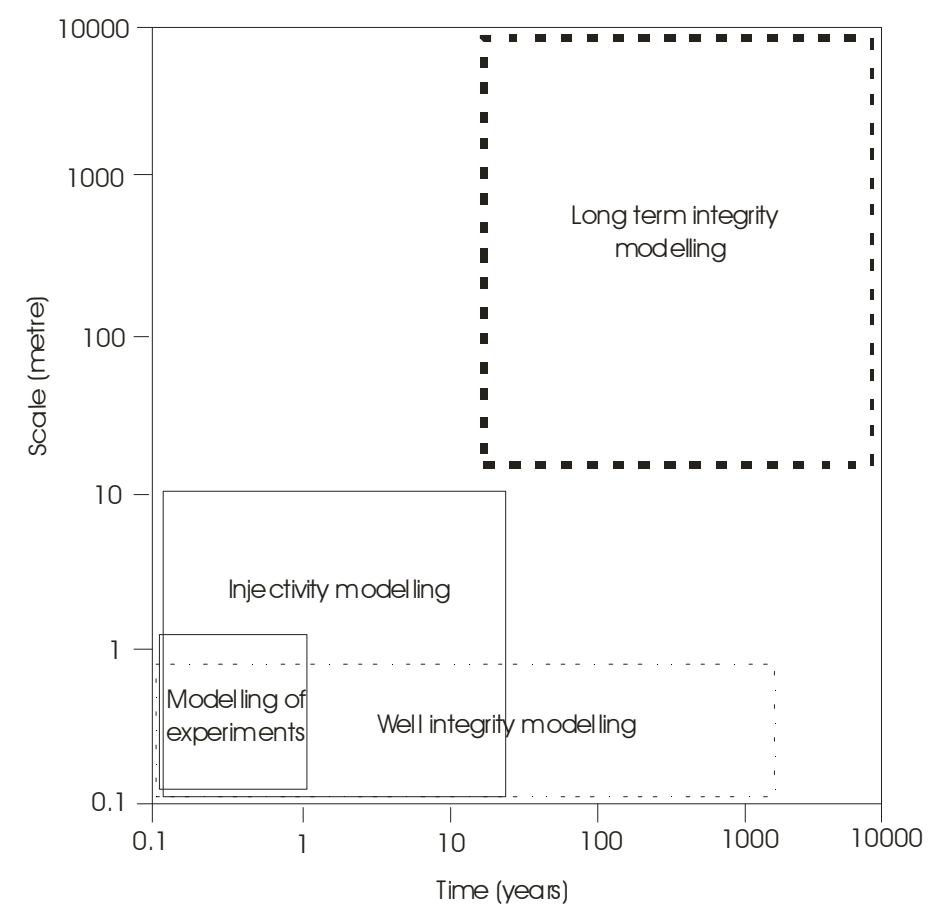




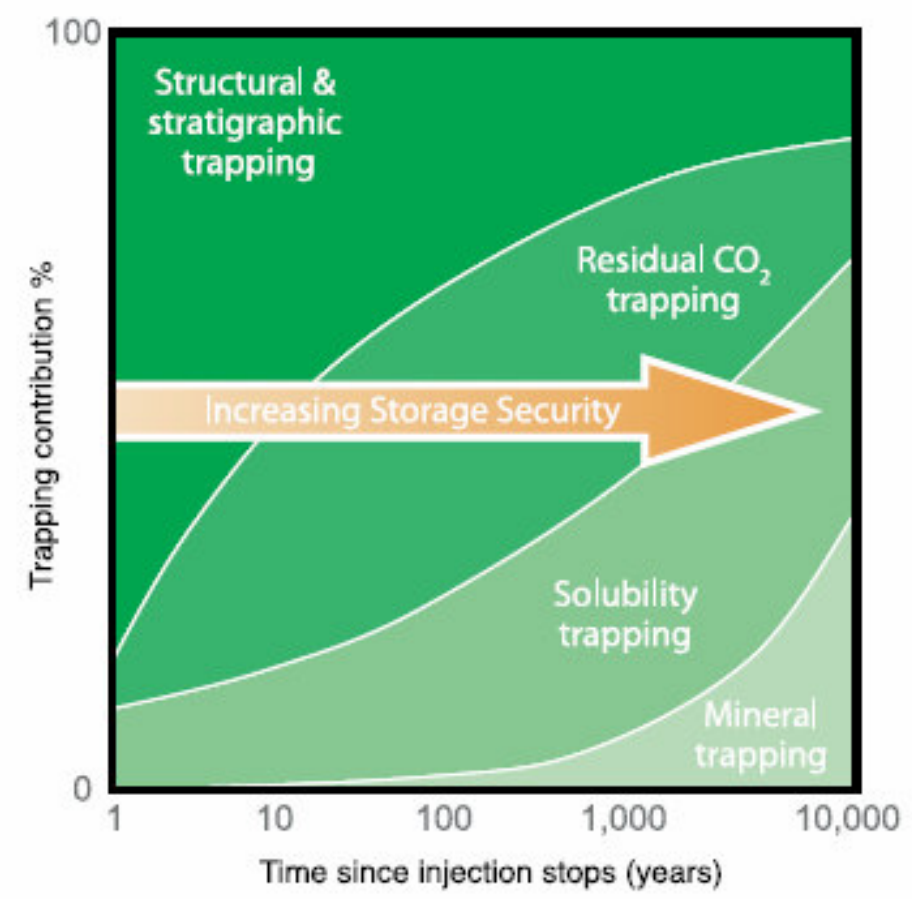




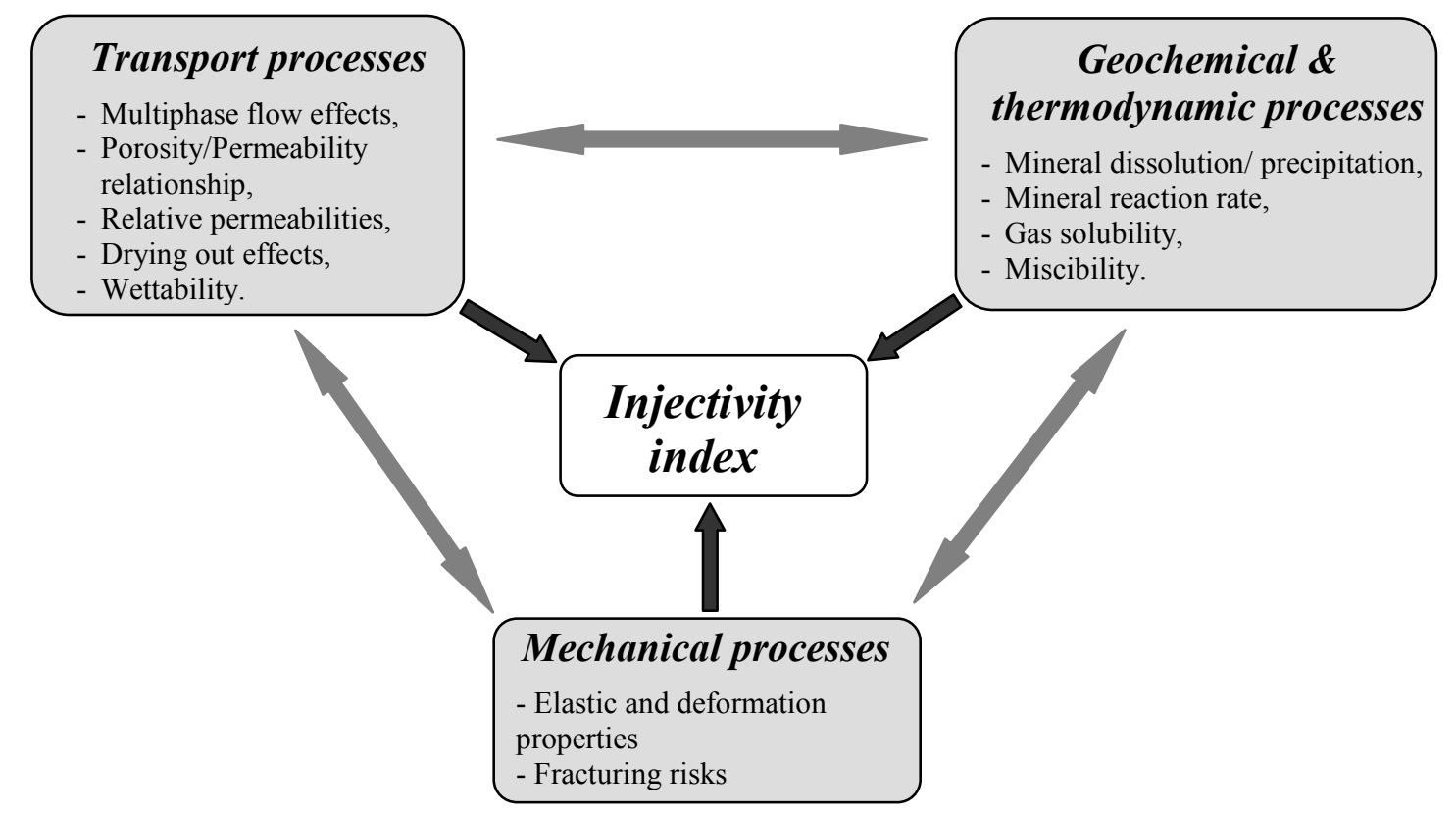




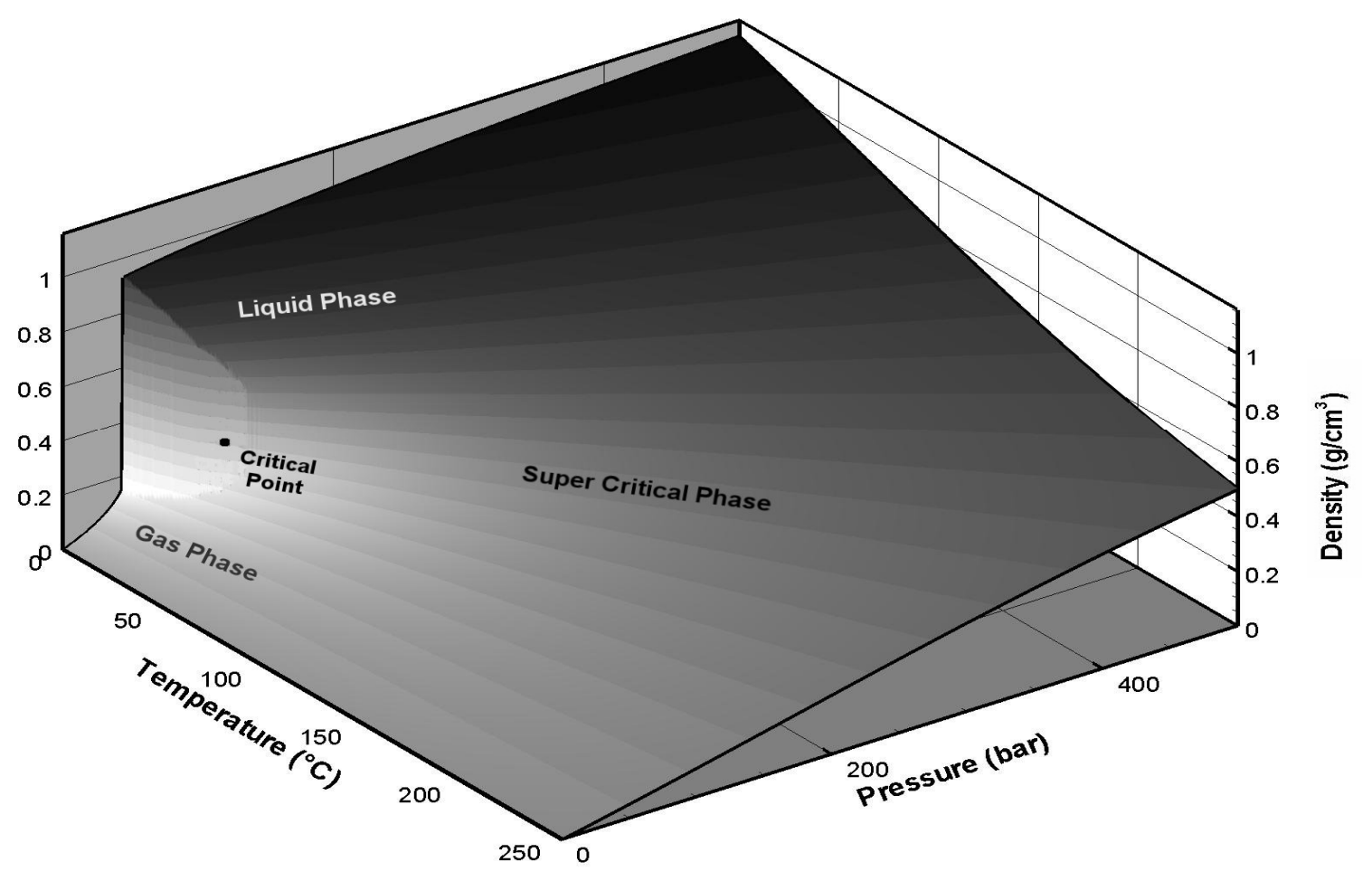




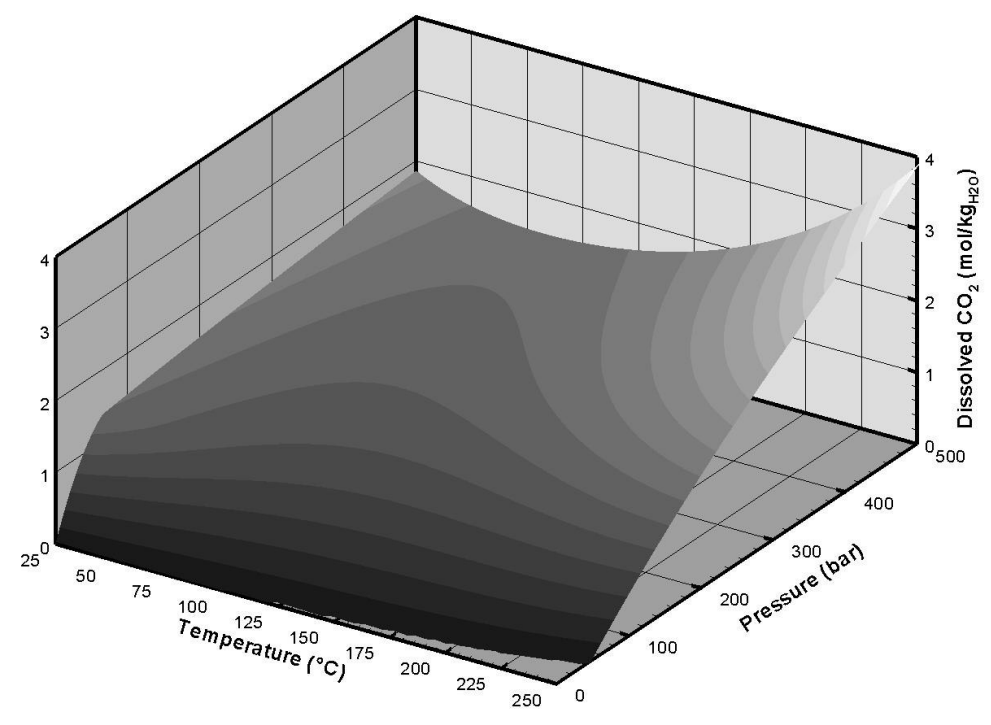




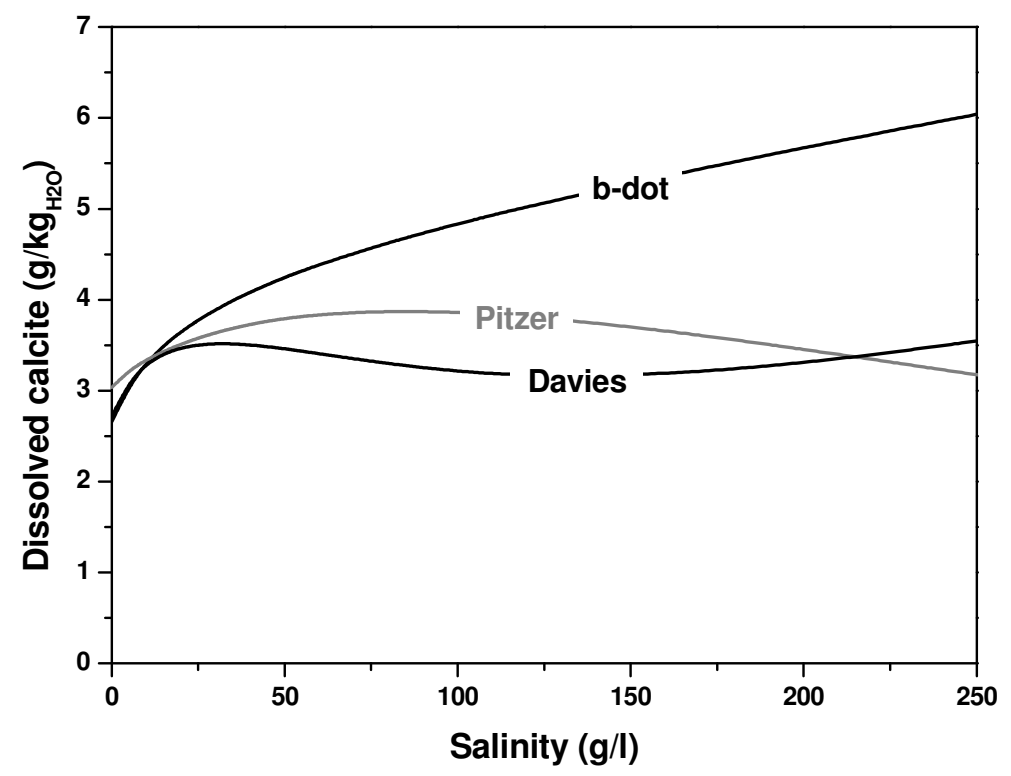



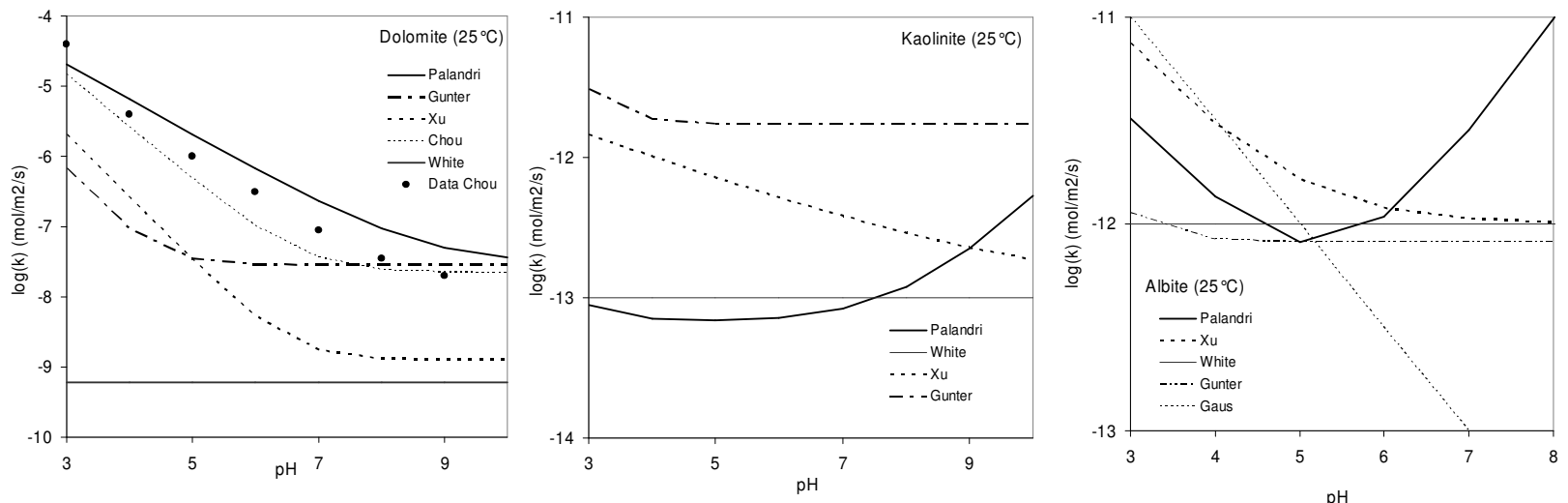


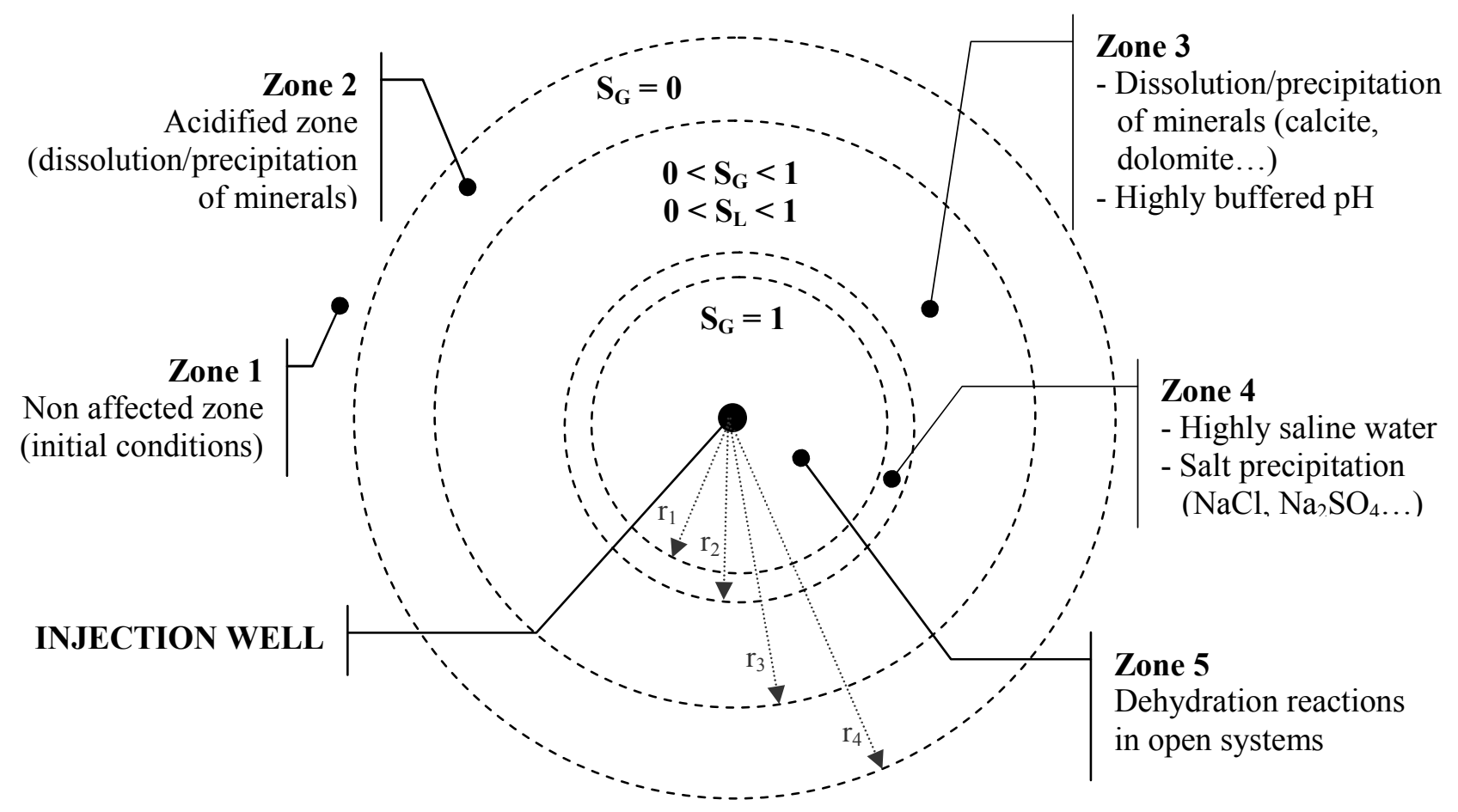


Burnol et al. (2006), Carey

and Lichtner (2007) and

Carey et al. (2007)

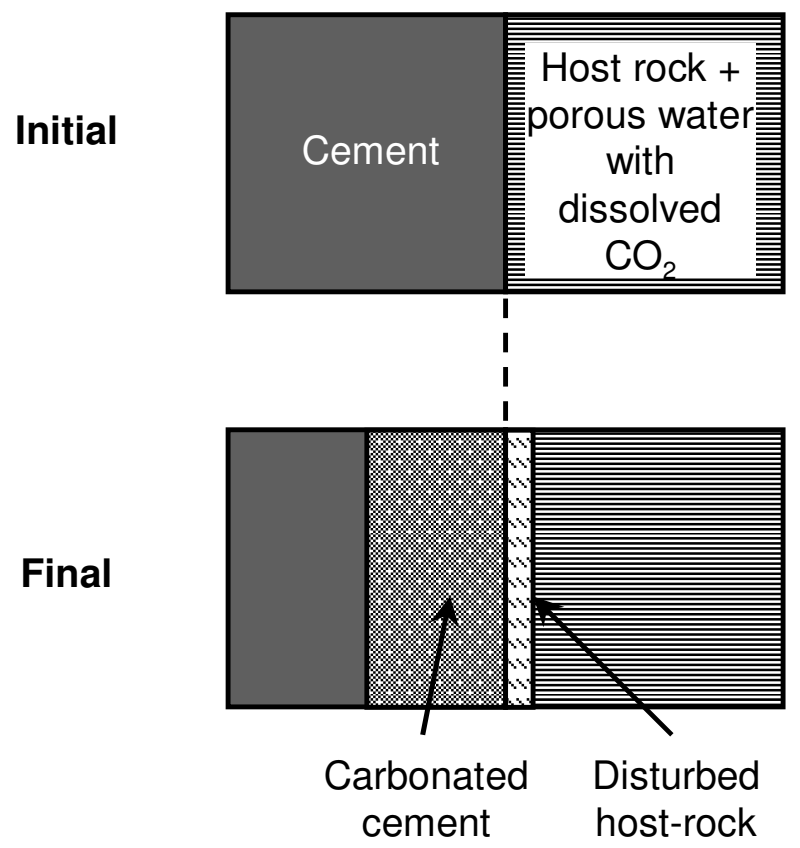

Pfingsten (2002) and Jacquemet (2006)

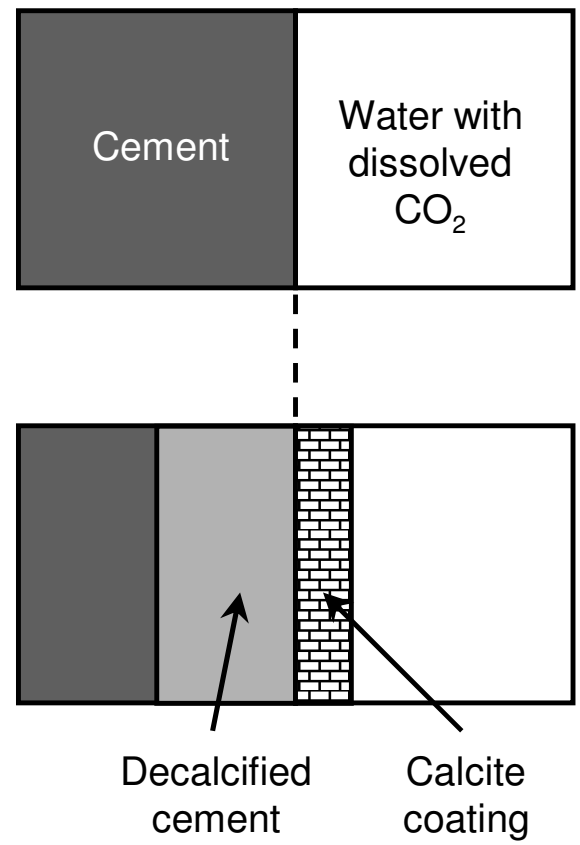

